\title{
Development of a Cast Iron Fatigue Properties Database for Use in Modern Design Methods
}

Final Technical Report

No. DOE/ID13852

DOE Contract No. DE-FC07-00ID13852

September 18, 2003

James D. DeLa'O, Ph.D.

Richard B. Gundlach

John M. Tartaglia, Ph.D.

Climax Research Services (CRS)

Wixom, MI 


\section{TABLE OF CONTENTS}

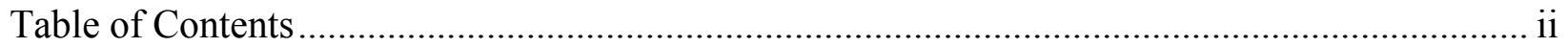

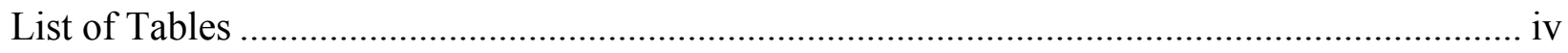

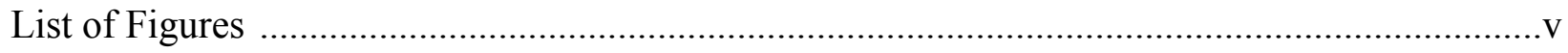

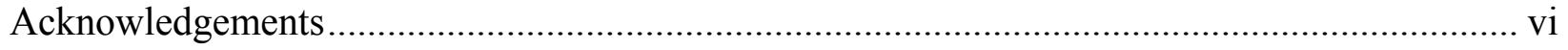

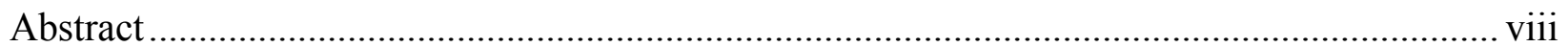

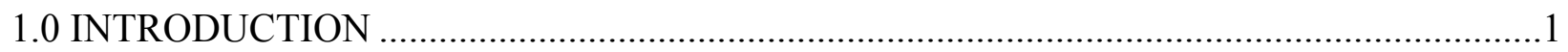

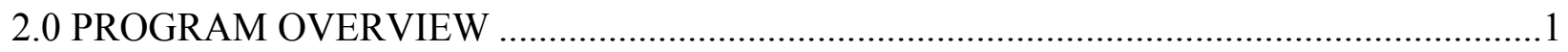

2.1 Objectives and Participants...................................................................................

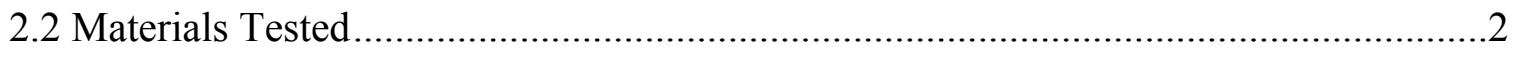

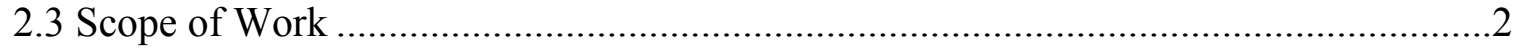

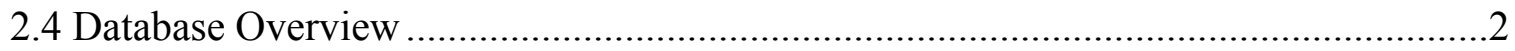

2.5 Methods of Cyclic Property Analysis .....................................................................

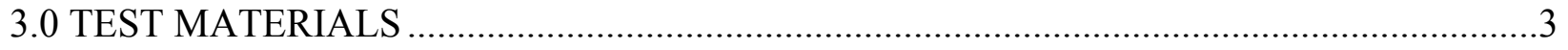

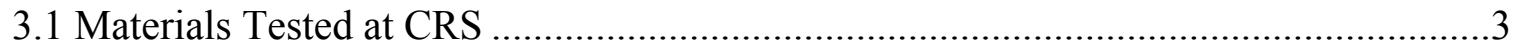

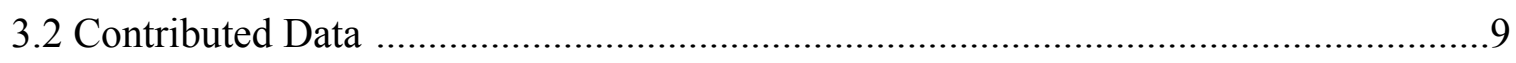

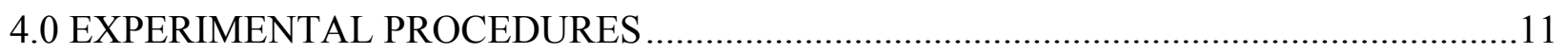

4.1 Chemical Analysis ..........................................................................................11

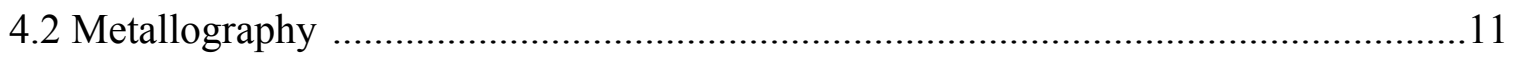

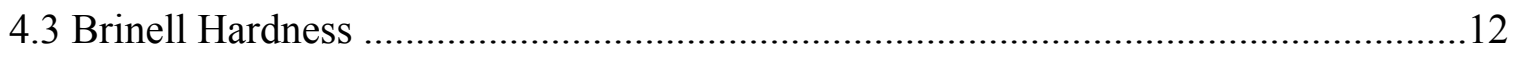

4.4 Monotonic Tension Testing ..................................................................................12

4.5 Monotonic Compression Testing ………………….........................................13

4.6 Strain-life Fatigue Testing ....................................................................................13

5.0 DETERMINATION OF CYCLIC PROPERTY PARAMETERS ……................................14

5.1 Conventional Strain-Life Method ..........................................................................14

5.2 Downing Method for Cast Iron ..........................................................................17

5.3 Determination of Cyclic Properties for Contributed Data ……………………….....22

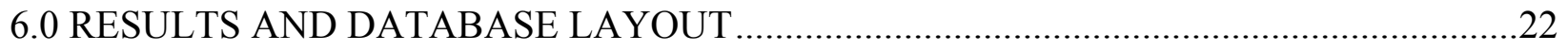

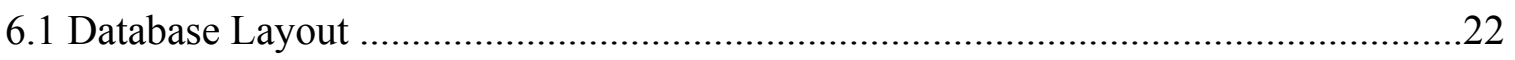

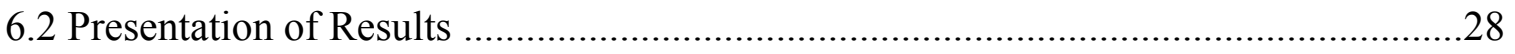

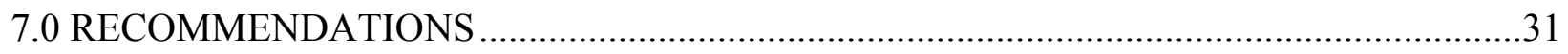

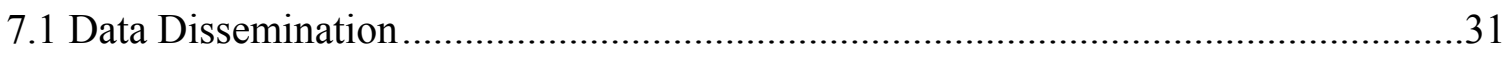

7.2 Toward a Comprehensive Graphitic Cast Iron Database .............................................31 


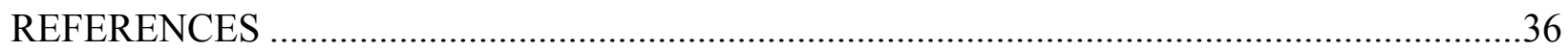

APPENDIX A Estimating Nodularity in CGI by Ultrasonic Velocity Measurement ..................37 


\section{LIST OF TABLES}

Table 3.1 Basic Quality Specifications for Materials Tested at CRS .........................................5

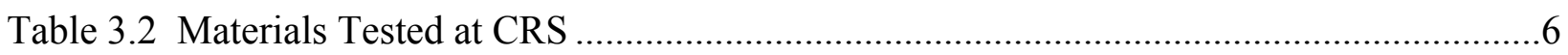

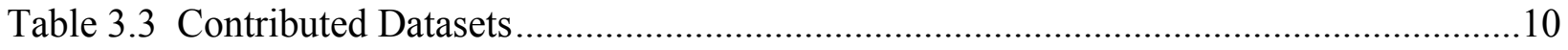

Table A1 Nodularity vs. Ultrasonic Velocity in CGI (Calibration Data) ..................................38 


\section{LIST OF FIGURES}

Figure 6.1a Database Map of Upper Levels of Disc 1 (ADI and Ductile Iron)........................23

Figure 6.1b Database Map of Upper Levels of Disc 2(CGI and Gray Iron) ...........................25

Figure 6.2 Detailed Database Map at the Results Level ...................................................27

Figure 7.1 Fatigue Behavior of Gray Iron at Various Grade Levels .......................................33

Figure 7.2 Fatigue Behavior of Gray Iron at Various Section Sizes .......................................34

Figure A1 Nodularity vs. Ultrasonic Velocity, Grade 300 Calibration Curve ..........................39

Figure A2 Nodularity vs. Ultrasonic Velocity, Grade 350 Calibration Curve ..........................39

Figure A3 Nodularity vs. Ultrasonic Velocity, Grade 400 Calibration Curve ..........................40 


\title{
ACKNOWLEDGMENTS
}

The authors gratefully acknowledge support for this work that was provided in part by a grant from the United States Department of Energy and the Cast Metals Coalition, Contract Number DE-FC07-00ID13852. The authors would like to thank the D.O.E. Project Officer, Mr. Robert Trimberger, as well as the Grant Administrator, Ms. Elaine Richardson, for their support and efforts through the duration of this program.

The authors are also grateful for the guidance and helpful discussions provided by the $5 \mathrm{H}$ and $5 \mathrm{I}$ committees of the American Foundry Society, without which this program would no have been possible. In particular the authors would like to acknowledge the effort and support of the AFS Research Director, Dr. Joseph Santner as well as the Steering Committee; the members of which are as follows:

\author{
Gerald A. Wilkinson (Chairperson), Kohler Co. \\ Prabhaker R. Gangasani, Dura Bar Division / Wells Manufacturing \\ Dr. Kathy L. Hayrynen, Applied Process, Inc. \\ Lawrence J. Jacobs, Advanced Cast Products \\ Laxmi C. Tandon, Gunite Corp.
}

The authors would like to express their deepest appreciation to Mr. Pejmun K. Mahlooji and Mr. Mathew Ullattikulam for their continued assistance throughout the course of this work. 


\section{ACKNOWLEDGEMENTS (Continued)}

\section{Industrial Partners}

The authors are grateful to our partners in industry who made this work possible by graciously contributing strain-life datasets and/or producing materials for testing. Participating organizations, in alphabetical order, are as follows:

Applied Process, Inc.

Livonia, MI 48150

Arvin-Meritor, Inc.

Troy, MI 48084

Bay Engineered Castings

De Pere, WI 54115

Bremen Castings, Inc.

Bremen, IN 46506

Citation Corp.

Texas Foundries, Inc.

Lufkin, TX 75903

Hi-Temp, Inc.

Northlake, IL 60164

TRW Automotive

Livonia, MI 48150

Waupaca Foundry, Inc.

Waupaca, WI 54981 


\begin{abstract}
A reliable and comprehensive database of design properties for cast iron is key to full and efficient utilization of this versatile family of high production-volume engineering materials. A database of strain-life fatigue properties and supporting data for a wide range of structural cast irons representing industry standard quality was developed in this program. The database primarily covers ASTM/SAE standard structural grades of ADI, CGI, ductile iron and gray iron as well as an austempered gray iron. Twenty-two carefully chosen materials provided by commercial foundries were tested and fifteen additional datasets were contributed by private industry. The test materials are principally distinguished on the basis of grade designation; most grades were tested in a $25 \mathrm{~mm}$ section size and in a single material condition common for the particular grade. Selected grades were tested in multiple sections-sizes and/or material conditions to delineate the properties associated with a range of materials of the given grade.

The cyclic properties are presented in terms of the conventional strain-life formalism (e.g., SAE J1099). Additionally, cyclic properties for gray iron and CGI are presented in terms of the Downing Model, which was specifically developed to treat the unique stress-strain response associated with gray iron (and to a lesser extent with CGI). The test materials were fully characterized in terms of alloy composition, microstructure and monotonic properties. The CDROM database presents the data in various levels of detail including property summaries for each material, detailed data analyses for each specimen and raw monotonic and cyclic stressstrain data. The CDROM database has been published by the American Foundry Society (AFS) as an AFS Research Publication entitled "Cast Iron Fatigue Properties Database for Modern Design Methods" (ISBN 0-87433-267-2).
\end{abstract}




\subsection{INTRODUCTION}

Modern strain-life data, in conjunction with current endurance modeling methods, enable designers to select optimal materials and design geometries, thus resulting in lighter products with energy efficient operation, longer and more predictable service life, and more energy efficient manufacture. With such data, product development time and cost can be dramatically reduced as well.

Graphitic cast iron is a family of high volume engineering materials which provides unique flexibility in terms of both manufacturing capabilities and mechanical properties. However, a recent review of the literature covering the years 1970 through 2000 (DeLa'O, 2001) revealed a paucity of self-consistent, well documented strain-life data for graphitic cast iron. Although a relatively small number of reliable, well documented datasets were identified, the data in the public domain were woefully inadequate to comprise a comprehensive design database for the many types and grades of graphitic cast iron. Without such data, cast iron may be used conservatively, resulting in unnecessarily massive and inefficient products, or it may become "invisible" to designers who will then select less appropriate materials, for which reliable design data are more readily available. The present program was conceived to directly address the need for a strain-life database for structural grades of graphitic cast iron.

\subsection{PROGRAM OVERVIEW}

\subsection{Objectives and Participants}

The broad objective of the present program was to develop a detailed and well documented strain-life database for graphitic cast iron. With funding provided by a grant from the U.S. Department of Energy/Cast Metals Coalition (DOE/CMC), Cooperative Agreement DE-FC0700ID13852, and with guidance provided by the American Foundry Society (AFS), Climax Research Services (CRS) conducted a program of strain-controlled fatigue testing and material characterization to develop design data for twenty two carefully selected materials. The test materials were contributed by high volume commercial foundries and heat treaters; the contributed materials were specified and produced to represent industry standards for quality. In addition, 15 strain-life data sets developed by private companies, both cast iron suppliers and end-users, were contributed and have been compiled in the same database. The contributions by these industrial participants are gratefully acknowledged. A full list of industrial partners who provided test materials and/or strain-life data is given on the acknowledgments page (page v.)

Guidance provided by the AFS Ductile and Gray Iron Research Committees and in particular by members of the Program Steering Committee (see page v) is also gratefully acknowledged.

\subsection{Materials Tested}

The database resulting from this work primarily represents ASTM/SAE standard grades of ductile iron, austempered ductile iron (ADI), compacted graphite iron (CGI), and gray iron. The 
sole exception is an austempered gray iron (AGI) for which a corresponding ASTM or SAE specification has not yet been developed. The test program conducted at CRS was intended to provide intrinsic material properties representative of high quality commercially produced iron. Thus, dedicated test castings (Y-blocks, keel-blocks and solid tapered cylinders) were used as test material sources and defect populations were limited to represent high quality, industry standard castings. In contrast, several of the contributed datasets were developed using test specimens machined from high quality cast parts. (Please refer to report section 3.0 "Test Materials" for more details.)

\subsection{Scope of Work}

In addition to determining cyclic properties for twenty-two carefully specified and produced groups of test castings, CRS conducted a broad range of tests to characterize the alloy chemistry, microstructure, and monotonic properties. Specifically, the test materials were subjected to the following tests:

- Chemical Analysis

- Microstructural Analysis

- Hardness Testing

- Monotonic Tension Testing

- Compression Testing (for compacted graphite and gray irons)

- Strain-controlled Fatigue Testing

\subsection{Database Overview}

The data are published on CDROM by the American Foundry Society (AFS) as an AFS Research Publication entitled "Cast Iron Fatigue Properties Database for Modern Design Methods" (ISBN 0-87433-267-2). The database contains information with various levels of detail to meet the needs of individual users. At the simplest level, a succinct, stand-alone data summary includes data for each material to promote ready access to the data and ease of use. Conversely, at the most detailed level, raw monotonic and cyclic stress-strain data are presented to provide maximum flexibility (primarily for users interested in applying their own in-house analysis methods). At the intermediate level, the results of material characterizations, monotonic property tests and cyclic property tests are tabulated on an individual specimen basis. Detailed analyses of monotonic and cyclic property data are also provided at this level. (Please refer to report section 6.0 "Results and Database Layout", below). With the exception of the ASCII files for monotonic tension and compression raw data, all files in the database are either in Microsoft Excel or Word formats. 


\subsection{Methods of Cyclic Property Analysis}

The database includes the results of two methods of cyclic property analysis. First, the conventional strain-life constants and cyclic stress-strain parameters (per ASTM E606 and SAE J1099) are provided for all materials. This strain-life formalism provides a number of advantages. These include familiarity on the part of many users, compatibility with virtually all endurance modeling software, and consistency with other databases (e.g., SAE J1099).

However, some of the underlying assumptions regarding material behavior that are implicit in the strain-life method are not strictly applicable to graphitic cast iron. Unlike most wrought materials, the stress-strain response of graphitic cast iron is asymmetrical with respect to zero stress, there is little or no linear elastic region and the unloading modulus is a function of the maximum applied stress (Gilbert, 1961, 1963 and 1964). Moreover, stress-strain hysteresis loops often do not reach a stabilized form during mechanical cycling. The degree to which these unique characteristics are exhibited depends on the type, quantity and distribution of the graphite microconstituent. This unique behavior is minimal in iron with nodular graphite (ductile iron) wherein there is a significant proportional limit (Gilbert, 1964), most pronounced in flake graphite iron (gray iron) wherein there is no proportional limit (Gilbert, 1963) and intermediate in iron with compacted graphite (CGI) (Palmer, 1976).

An alternative method of modeling strain-controlled fatigue behavior has been developed at the University of Illinois by Downing (Downing, 1983) to directly address the aforementioned unique properties of cast iron. The method developed by Downing has been applied to analyze the cyclic property data for the gray iron and CGI in this program and the Downing parameters are included in addition to the conventional strain-life parameters in the database. Although, the Downing model is less familiar than the conventional strain-life model, it is tailored for the unique behavior of cast iron and the parameters can be used with widely available commercial software packages for endurance modeling.

\subsection{TEST MATERIALS}

\subsection{Materials Tested at CRS}

Only those materials used for structural applications, wherein fatigue behavior is of paramount importance, were considered for testing. Furthermore, to ensure the maximum impact of the database, the test materials were primarily selected on the basis of current commercial production volume. Consequently, twenty-one of the twenty-two test materials are represented by current ASTM and/or SAE standards.

Relatively new materials with uniquely beneficial engineering properties, and for which there is development interest on the part of end-users, were also considered. The development of engineering applications with such new materials is impeded by a lack of mechanical property data. One such material, an austempered gray iron, was tested in this program. 
As previously mentioned, the objective of testing was to produce intrinsic property data, that is, data largely unaffected by casting defects that might be associated with a particular cast part. Therefore, standard test castings (e.g., Y-blocks, keel blocks and solid tapered cylinders) were used. Additionally, relevant microstructural features and maximum allowable levels of defect populations were specified to represent current industry-standard production quality. Please refer to Table 3.1 for more details.

\subsubsection{Qualification testing}

Randomly selected samples from each set of contributed castings were subjected to qualification testing. Metallographic analysis was conducted to ensure that basic quality specifications (as described above) were met. Qualification testing was also used to verify that the tested castings met the mechanical property requirements of the corresponding ASTM and SAE standard specifications. Since some of the mechanical property ranges specified in the standards overlap or vary continuously from grade to grade (e.g., hardness and tensile properties), the results of qualification testing were also used to verify that the properties of the test materials varied approximately evenly from grade to grade. Otherwise, two nominally different casting grades might in actuality be nearly identical, thereby leading to redundant datasets.

CRS provided strain-life data only for materials that were first qualified in this manner.

\subsubsection{Ductile iron}

The ductile iron tested in this program (Table 3.2) was primarily specified in terms of the five structural grades defined in ASTM Standard A 536-84 (Reapproved 1999), wherein minimum requirements are based on monotonic tensile properties. For each of the five ASTM A 536 grades (with the exception of Grade 120-90-02) there are corresponding grades defined on the basis of hardness in SAE Standard J434 JUN1986. All eight tested materials met the requirements of both the ASTM and SAE specifications. (Austempered ductile iron is treated separately in the following report subsection.)

In addition to the five grade designations, the materials were further specified on the basis of section size and material condition, parameters that are well-known to affect the mechanical behavior of ductile iron. One-inch section sizes (either Y-blocks or keel-blocks) were tested for each of the five basic grades (with the exception of ASTM Grade 80-55-06) spanning the full strength/hardness range specified by the ASTM and SAE standards. Grade 80-55-06 ductile iron was omitted from the test matrix because of an abundance of contributed data for this grade, as well as high quality data already in the literature (DeLa'O, 2001; Tartaglia, 2000).

The properties required for the lowest strength grade (ASTM 60-40-18 / SAE D4018) are commonly obtained by annealing, either a full ferritizing anneal (hypercritical anneal) or an anneal at subcritical temperature. This grade was tested in a $25 \mathrm{~mm}$ section size in three different conditions: specifically, after a full ferritizing anneal, after a subcritical anneal, and in the as-cast condition. To minimize mechanical property variations that might result from variations in annealing procedures, both the supercritical and subcritical annealing operations were conducted by the same commercial source. 
Table 3.1 Basic Quality Specifications for Materials Tested at CRS

\begin{tabular}{|c|c|}
\hline \multicolumn{2}{|c|}{ ADI and Ductile Iron } \\
\hline Nodule Count & $\geq 100 \mathrm{~mm}^{-2}$ \\
\hline Nodularity & $\geq 90 \%$ \\
\hline Graphite Distribution & Free from flotation and clustering \\
\hline $\begin{array}{l}\text { Percent Intercellular Carbides and } \\
\text { Nonmetallic Inclusions }\end{array}$ & $<0.5 \%$ \\
\hline Percent Porosity & $<1 \%$ \\
\hline \multicolumn{2}{|c|}{ Alloy Requirements (ADI only) } \\
\hline Carbon & $3.50 \pm 0.20$ \\
\hline Silicon & $2.50 \pm 0.20$ \\
\hline Manganese & $0.30 \pm 0.05$ \\
\hline Copper & $0.50 \pm 0.05$ \\
\hline Nickel & $0.25 \pm 0.05$ \\
\hline Molybdenum & Residual \\
\hline \multicolumn{2}{|c|}{ CGI } \\
\hline \multirow{2}{*}{ Graphite Structure } & $20-50 \%$ Nodularity \\
\hline & Free of ASTM A 247 Type III Graphite \\
\hline $\begin{array}{c}\text { Percent Intercellular Carbides and } \\
\text { Nonmetallic Inclusions }\end{array}$ & $<0.5 \%$ \\
\hline Percent Porosity & $<1.0 \%$ \\
\hline \multicolumn{2}{|c|}{ Gray Iron } \\
\hline Graphite Structure & Primary Type A Flakes \\
\hline Alloy Content & Mild Alloy \\
\hline $\begin{array}{c}\text { Percent Intercellular Carbides and } \\
\text { Nonmetallic Inclusions }\end{array}$ & $<0.5 \%$ \\
\hline Percent Porosity & $<1.0 \%$ \\
\hline
\end{tabular}

The properties of ASTM Grade 65-45-12 are typically obtained either as-cast or by annealing. This material was tested only in the as-cast condition.

The properties of the highest strength grade, ASTM Grade 120-90-02, are most commonly obtained by quenching and tempering. This grade was tested only in a quenched and tempered condition. 
Table 3.2 Materials Tested at CRS

\begin{tabular}{|c|c|c|}
\hline \multicolumn{3}{|c|}{ Austempered Ductile Iron: ASTM A 897-02 } \\
\hline \multicolumn{2}{|c|}{ ASTM Grade } & Section Size \\
\hline \multicolumn{2}{|c|}{$125-80-10$} & $25 \mathrm{~mm}$ Y-block \\
\hline \multicolumn{2}{|c|}{$150-100-7$} & $25 \mathrm{~mm}$ Y-block \\
\hline \multicolumn{2}{|c|}{$175-125-4$} & $25 \mathrm{~mm}$ Y-block \\
\hline \multicolumn{2}{|c|}{$200-155-1$} & $25 \mathrm{~mm}$ Y-block \\
\hline \multicolumn{3}{|c|}{ Ductile Iron: ASTM A 536-84 (Re 1999) } \\
\hline ASTM Grade & Material Condition & Section Size \\
\hline \multirow{3}{*}{$60-40-18$} & As-cast & $25 \mathrm{~mm}$ Keel block \\
\hline & Subcritical Anneal & $25 \mathrm{~mm}$ Keel block \\
\hline & Full Anneal & $25 \mathrm{~mm}$ Y-block \\
\hline $65-45-12$ & As-cast & $25 \mathrm{~mm}$ Keel block \\
\hline \multirow{3}{*}{$100-70-03$} & As-cast & $25 \mathrm{~mm}$ Keel block \\
\hline & \multirow{2}{*}{ Normalized } & $25 \mathrm{~mm}$ Keel block \\
\hline & & $76 \mathrm{~mm}$ Y-block \\
\hline $120-90-02$ & Quenched and Tempered & $25 \mathrm{~mm}$ Keel block \\
\hline \multicolumn{3}{|c|}{ Compacted Graphite Iron: ASTM A 842-85(Re 1997) (Enhanced: 20\% - 50\% Nodularity) } \\
\hline "ASTM Grade" & Material Condition & Section Size \\
\hline 300 & As-Cast & $25 \mathrm{~mm}$ Y-block \\
\hline 350 & As-Cast & $25 \mathrm{~mm}$ Y-block \\
\hline 400 & As-Cast & $25 \mathrm{~mm}$ Y-block \\
\hline \multicolumn{3}{|c|}{ Gray Iron: ASTM A 48-00 } \\
\hline \multicolumn{2}{|c|}{ ASTM Grade } & Section Size \\
\hline \multicolumn{2}{|c|}{ 20B } & $25 \mathrm{~mm}$ Y-block \\
\hline \multirow{3}{*}{\multicolumn{2}{|c|}{$30 \mathrm{~B}$}} & $13 \mathrm{~mm}$ Round \\
\hline & & $25 \mathrm{~mm}$ Y-block \\
\hline & & 76 mm Y-block \\
\hline \multicolumn{2}{|c|}{$35 \mathrm{~B}$} & $25 \mathrm{~mm}$ Y-block \\
\hline \multicolumn{2}{|c|}{$40 \mathrm{~B}$} & $25 \mathrm{~mm}$ Y-block \\
\hline \multicolumn{3}{|c|}{ Austempered Gray Iron: No Standard Specification } \\
\hline Base Iron & Material Condition & Section Size \\
\hline Class 30B & Austempered & $25 \mathrm{~mm}$ Y-block \\
\hline
\end{tabular}


ASTM Grade 100-70-03 can be obtained either as-cast, by normalizing or by quenching and tempering. Materials representing this grade were tested in a $25 \mathrm{~mm}$ section size in both as-cast and normalized conditions. Additionally, ductile iron of this grade is typically obtained in heavier sections with the aid of heat treatment. Grade 100-70-03 was also tested in a $76 \mathrm{~mm}$ section size (Y-block) after normalizing. Both of the normalized materials were heat treated by the same commercial source.

\subsubsection{Austempered ductile iron}

The ADI tested at CRS was specified primarily in terms of ASTM Standard A 897-02. A corresponding SAE standard was not adopted until March 2003 (SAE J2477 MAR2003) and therefore was not available at the time the test materials were specified for this program. Of the five grades of ADI specified in ASTM A 897-02, four were selected for testing (Table 3.2). The highest strength grade (i.e., 230-185) was not tested because it is not generally used as a structural material

Although the mechanical properties of ADI, like those of other types of cast iron, are section size dependent, it was outside the scope of this program to delineate section sensitivity for all types and grades of iron. Therefore, to more clearly demonstrate the grade dependence of fatigue properties in ADI, all four selected grades of ADI were tested in a single commonly produced section size, $25 \mathrm{~mm}$ (Y-block) castings.

To further ensure that the results would reveal the grade dependence of fatigue properties, without complications arising from differences in base iron or heat treatment methods, the base iron for all four grades of ADI was produced from two nominally identical heats at one foundry. The test castings for each of the four grades were randomly selected from each of the two heats. Finally, heat treatment parameters were developed and the four groups austempered by a single commercial source.

\subsubsection{Compacted graphite iron}

The CGI tested at CRS was specified largely in terms of ASTM Standard A 842-85 (Reapproved 1997). It is noteworthy, that the ASTM specification requires a minimum of 80 percent ASTM A 247 Type IV graphite; therefore, the percentage of graphite in nodular form is limited to a maximum of 20 percent. However, for a number of reasons including manufacturing concerns, commercial CGI production in North America is predominated by iron with 20 through 50 percent nodularity. The recent SAE specification of CGI, SAE Standard J1887 JUL2002, includes two "high nodularity" grades with these nodularity limits (i.e., $20-50 \%$ ), but the remaining five grades, like the ASTM Grades, are defined with a maximum nodularity of 20 percent. The SAE specification was released well after material testing was underway and it was not used to specify materials for this program. Although the CGI tested in this program was otherwise defined in terms of the aforementioned ASTM standard, the nodularity range for the test materials was specified on the basis of typical commercial production $(20 \%-50 \%$ nodularity) rather than the ASTM standard. 
The three most commonly produced grades, ASTM A 842 Grades 300, 350 and 400, were tested in this program (Table 3.2). Although the mechanical properties of CGI, like those of other types of cast iron, are section size dependent, it was outside the scope of this program to delineate section sensitivity for all types and grades of iron. Therefore, the three selected grades of CGI were tested in a single section size, $25 \mathrm{~mm}$ (Y-block) castings, to demonstrate the grade dependence of fatigue properties in CGI. All three test materials were produced and contributed by the same foundry to more clearly delineate the effects of grade distinction.

\subsubsection{Sorting CGI test materials by nodularity}

During qualification testing, metallographic analysis of selected samples from the three sets of CGI revealed graphite morphologies that fell outside the specified range of 20 through 50 percent nodularity.

To surmount this obstacle, all of the CGI test materials were sorted according to nodularity as determined by ultrasonic velocity measurements. The results of ultrasonic velocity testing were calibrated for nodularity determination on the basis of metallographic analyses performed on selected specimens. Although others have used this method with mixed success (Fowler, 1984), CRS carefully developed the method through several iterations of testing. A distinct linear calibration curve was developed for each of the three test materials, each curve having a coefficient of determination $\left(\mathrm{r}^{2}\right)$ in excess of 0.9 .

On the basis of the calibration curves, specimens with graphite morphologies falling within the 20 through 50 percent nodularity range were identified for further testing. (Please refer to Appendix A, "Calibration Curves; Nodularity vs. Ultrasonic Velocity in CGI", for more details).

\subsubsection{Gray iron}

With one exception, the gray iron tested at CRS was specified in terms of ASTM Standard A 4800 (Table 3.2). This standard defines the various classes of gray iron on the basis of the properties of standard cast test bars that are to be poured concurrently with the specified castings. The complete class designation then must refer to the type of standard cast test bar for which the properties are specified. For example, Class 30B refers to castings poured concurrently with standard Type B test bars (30 $\mathrm{mm}$ diameter rounds), the latter having properties that must meet the requirements of Class 30.

The gray iron tested at CRS was specified in terms of standard Type B cast test bars. Concurrently poured Y-blocks and rounds (i.e., cylindrical rods) of various section sizes were tested to develop the gray iron portion of the strain-life database; the standard Type B castings were tested only to verify the class requirements. The properties of the actual test materials were not directly specified, that is, they were simply allowed to "float" in the same way that the properties of actual cast parts of a given class vary freely with section size. For example, the properties of an automotive Class 30B cylinder block can vary between heavy sections located high in the bulkheads and thin sections of the bulkheads located nearer to the bearing saddles. The cylinder block iron is nonetheless Class 30B if the concurrently poured Type B test castings meet the requirements of ASTM A 48 Class 30. 
Four classes of gray iron were selected for testing covering a wide range of the commonly used structural classes of gray iron. Classes 20B, 30B, 35B and 40B were all tested in 25-mm cast (Y-block) section sizes. Since the properties of gray iron are well known to be section size dependent, Class 30B was also tested as $13 \mathrm{~mm}$ rounds and $76 \mathrm{~mm}$ Y-block castings, thus covering a significant range in section size for Class 30B iron. Moreover, all three section sizes of Class 30B were poured concurrently to clearly demonstrate the effects of section size alone on the properties of the material. All six of these materials were tested in the as-cast condition.

Finally, a Class 30B iron was austempered prior to testing. Although there is currently no ASTM or SAE specification for this material, it offers unique engineering properties and is of considerable development interest to end-users. CRS is unaware of strain-life data for austempered gray iron (AGI) in the public domain. However, the basic mechanical properties of a similar AGI have previously been reported (Kovacs, 1993).

A single commercial foundry provided the base iron for all seven materials.

\subsection{Contributed Data}

Datasets developed by private industry for fifteen materials (Table 3.3) were provided and have been included in the database. Of the fifteen materials, eleven are ductile iron, three are ADI and one is gray iron.

\subsubsection{Contributed ductile iron datasets}

The eleven strain-life datasets variously represent ductile iron from cast parts and from standard test castings. The materials were tested in both the as-cast and heat treated conditions. The datasets were compiled in the database.

\subsubsection{Contributed ADI datasets}

The three contributed ADI datasets cover the three intermediate strength grades that are specified in ASTM Standard A 897-02. These data were contributed by a commercial heat treater with a long established record of producing industry standard ADI. Detailed material characterizations were not provided with each dataset; instead, these datasets were developed to be "generally representative" of ADI of approximately $25 \mathrm{~mm}$ section size for these three grades.

An analogous dataset from the same source was developed to cover the low strength/high ductility grade of ADI, ASTM A 897 Grade 125-75-10. Although, this dataset was not contributed specifically for use in this program, the data have been published in the open literature (Rio Tinto Iron and Titanium, 1998). The data are included here for the sake of completeness. 


\subsubsection{Contributed gray iron dataset}

A dataset based on specimens extracted from gray iron brake rotor castings was contributed. The brake rotors were approximately $25-\mathrm{mm}$ thick and the material was tested in the as-cast condition. The material was specified as an SAE J431 G3000. Although data was not provided for ASTM standard test castings, the properties were consistent with an ASTM A 48-00 Class 30 .

Table 3.3 Contributed Datasets

\begin{tabular}{|c|c|c|}
\hline \multicolumn{3}{|c|}{ Austempered Ductile Iron: ASTM A 897-02 } \\
\hline ASTM Grade & Material Condition & Casting Description \\
\hline $125-80-10^{1}$ & Austempered & $\sim 25 \mathrm{~mm}$ section \\
\hline $150-100-07$ & Austempered & $\sim 25 \mathrm{~mm}$ section \\
\hline $175-125-04$ & Austempered & $\sim 25 \mathrm{~mm}$ section \\
\hline 200-155-01 & Austempered & $\sim 25 \mathrm{~mm}$ section \\
\hline \multicolumn{3}{|c|}{ Ductile Iron: ASTM A 536-84 (Re 1999) } \\
\hline ASTM Grade & Material Condition & Casting Description \\
\hline \multirow{4}{*}{$65-45-12$} & As-cast & Flange Half Differential $(\sim 25 \mathrm{~mm})$ \\
\hline & As-cast & Keel block \\
\hline & As-cast & $25 \mathrm{~mm}$ Y-block \\
\hline & Full Anneal & $25 \mathrm{~mm}$ Y-block \\
\hline \multirow{6}{*}{$80-55-06$} & As-cast & Brake Caliper Casting ( $25 \mathrm{~mm})$ \\
\hline & As-cast & Keel block \\
\hline & As-cast & $25 \mathrm{~mm}$ diameter solid cylinder \\
\hline & As-cast & $25 \mathrm{~mm}$ Y-block \\
\hline & As-cast & Flange Half Differential $(\sim 25 \mathrm{~mm})$ \\
\hline & Normalized & $25 \mathrm{~mm}$ diameter solid cylinder \\
\hline $100-70-03$ & Normalized & $25 \mathrm{~mm}$ Y-block \\
\hline \multicolumn{3}{|c|}{ Gray Iron: ASTM A 48-00 } \\
\hline \multicolumn{2}{|c|}{ ASTM Grade } & Casting Description \\
\hline \multicolumn{2}{|c|}{30} & Brake-rotor casting $(\sim 25 \mathrm{~mm})$ \\
\hline
\end{tabular}

Footnote:

1. Data from open literature (included for completeness). 


\subsection{EXPERIMENTAL PROCEDURES AND ANALYTICAL METHODS}

The experimental procedures and analytical methods described in this chapter pertain to materials tested at CRS. The contributed data were generally developed using similar methodologies. Some differences in methodology that are deemed noteworthy are footnoted in the results tables in the database (see Chapter 5).

\subsection{Chemical Analysis}

An analysis of alloy chemistry was conducted on each of two samples extracted from randomly selected castings from each group of test material, with the exception of gray iron. In each analysis, the concentrations of fourteen elements were determined. All elemental concentrations were determined using optical emission spectrometry (OES) in accordance with ASTM standard E415-99a, except carbon, nitrogen, and sulfur, which were determined using combustometric methods (LECO) in accordance with ASTM standard E1019-00, and copper and magnesium, which were determined by atomic absorption (AA) spectrophotometry in accordance with ASTM standard E1024-97.

Gray iron analyses were conducted on chill cast specimens poured concurrently with each group of material. All elemental concentrations were determined using optical emission spectrometry (OES) in accordance with ASTM standard E415-99a.

\subsection{Metallography}

Typically three metallographic specimens were prepared and analyzed for each test material. In the case of the ASTM Standard A 48 gray iron, metallography was conducted both on the standard Type B test castings and the castings used for fatigue testing (i.e., Y-blocks and rounds) for each group.

Transverse cross-sections were extracted from the gage section of tensile bars, mounted and polished using standard metallographic techniques in accordance with ASTM standard E3-01. The samples were final polished using colloidal silica media with a 0.05 um particle size. The samples were photographed at two or three appropriate magnifications in the as-polished condition and after etching with $2 \%$ Nital.

Image analysis for nodularity and nodule count was performed in accordance with ASTM standard A247-67 (1998) on ductile iron, ADI and CGI specimens. Image analysis was conducted on gray iron specimens, for flake size and type in accordance with ASTM standard A247-67 (1998). In addition, the eutectic cell count was determined for gray iron specimens after etching in Keller's reagent. Finally, the ferrite content was determined by automated image analysis in materials with a ferrite/pearlite matrix. The matrix phase composition was determined by visual inspection in all other materials. 


\subsection{Brinell Hardness}

Brinell hardness measurements were conducted on the shoulders of fractured tensile bars. One impression was made in each shoulder. All Brinell hardness tests were performed in accordance with ASTM standard E10-01 using a 3000-kg load.

\subsection{Monotonic Tension Testing}

Tension specimens were tested to determine standard tensile properties [i.e., $0.2 \%$ offset yield strength (YS), ultimate tensile strength (UTS), total elongation $(\% \mathrm{El})$, and reduction in area $(\% \mathrm{RA})]$ for all 22 test materials. Additionally, the monotonic tensile stress-strain response was characterized for a subset of the specimens in terms of elastic modulus and/or Poisson's ratio as well as monotonic strength coefficient $(\mathrm{K})$ and monotonic strain hardening exponent $(\mathrm{n})$. Monotonic strength coefficients and strain hardening exponents were determined for ductile iron, ADI and CGI, but not for gray iron.

Tensile tests were conducted at room temperature in accordance with ASTM standard E8-01. Tests were conducted on standard round tension specimens with 0.5 -inch gauge diameter and 2.0-inch gauge length. In isolated cases, tension specimens conforming to the requirements of "small-size specimens proportional to the standard specimen", as defined in ASTM E8, were used when necessitated by material size constraints. Specimen dimensions are indicated in footnotes that are presented with the test results.

For determining the room temperature stress-strain response with its concomitant coefficients, CRS employed strain gauges (for precision modulus and Poisson's ratio determination) and an extensometer (for determination of the strength coefficient and strain hardening exponent). These tests were conducted in accordance with ASTM standard E111-97 for elastic modulus, ASTM standard E132-97 for Poisson's ratio and ASTM standard E646-00 for K and n values.

For standard tension tests, an initial strain-rate of $0.3 \%$ per minute was imposed until the yield strength was exceeded; after yield, the strain-rate was increased to $10 \%$ per minute. The total elongation was measured by reassembly of the samples and physical measurement of the final gauge length. When the test included elastic modulus or Poissson's ratio determination, a smaller initial strain rate, $(0.2 \%$ per minute $)$ was used.

It should be noted that the strain gage data from three tensile tests conducted for each of four groups of gray iron (Class 30B, 35B and 40B, 1-inch sections as well as Class 30B, 3-inch section) contained "noise" in the form of spurious data points in the low stress portion of the curve. The bad data points were easily identified as outliers and the data were filtered prior to their use for determination of the elastic modulus. Data from the same samples were also used in secant modulus regressions as part of the determination of the Downing cyclic-stress strain parameters (see Section 5.2). The secant modulus regressions are conducted over a stress range that was largely unaffected by the noise in the data. Consequently, the data were not filtered for this application. The raw stress-strain data are presented in unfiltered form. 


\subsection{Monotonic Compression Testing}

Compression testing was conducted in accordance with ASTM test method E9-89a(2002). Specimen dimensions are indicated in footnotes that are presented with the test results. The $0.2 \%$ offset yield strength (YS) was determined. In addition, strain gages were attached to the specimens for the determination of Poisson's ratio or elastic modulus in accordance with ASTM standards E132-97 and E111-97, respectively. The specimens were strained at $0.2 \%$ minute until $1 \%$ strain.

\subsection{Strain-life Fatigue Testing}

Room temperature, strain-controlled fatigue tests were conducted on samples from all twentytwo materials. The samples were tested following the guidelines of ASTM standard E606-92 (1998) to determine the strain-life curve for each material over the range from about 100 cycles to 1,000,000 cycles. Generally, three specimens were tested at each of six to seven strain levels with the specific strain levels chosen to provide fatigue lives that are evenly distributed on a logarithmic scale. Guidelines provided in ASTM Standard E 739-91 for design allowable strainlife data suggest 12 to 24 test specimens per material with a minimum of 50 to 75 percent replication. With three test specimens per strain level, the degree of replication in the present work is approximately $66 \%$.

All test specimens were machined and longitudinally polished in general accordance with the recommendations contained in Appendix X3 of ASTM standard E606-92 (1998). The geometry of the samples met the requirements of ASTM Standard E466-96 (2002). The dimensions were also largely consistent with the requirements of ASTM standard E606-92 (1998), with the exception that a more generous blending radius (blending radius $=8 \mathrm{X}$ gage diameter) was used.

Test specimens were machined with a 0.314 -inch $(8-\mathrm{mm})$ gage diameter, 0.628 -inch $(16-\mathrm{mm})$ gage length, 2.51-inch $(64-\mathrm{mm})$ blending radius, and $0.590(15-\mathrm{mm})$ diameter grip ends, with the exception of two sets of specimens. The ASTM A 48 Class $30 \mathrm{~B}$ tapered cylinders had a mean diameter of approximately 0.55 inch, thus forcing a reduction in the diameter of the grip ends to 0.5 inch (12.7-mm). The second exception was the ASTM A-897 Grade 200-155-1 ADI. At high strain amplitudes the resulting load exceeds the gripping force of the hydraulic grips. All specimens from this group that were tested with a total strain amplitude greater than or equal to $0.9 \%$ (8 specimens were involved) were machined with a smaller gage diameter. With the exception of the diameter of the grip ends, all dimensions were reduced proportionally from the standard specimen; thus, the eight reduced samples had a gage diameter of 0.27 inch (7-mm), a gage length of 0.55 inch (14-mm), a blending radius of 2.2 inches (56- $\mathrm{mm})$ and grip end diameters of 0.590 inches $(15-\mathrm{mm})$.

The tests were performed using a triangular waveform at a constant strain rate of $2 \%$ per second for ductile iron and ADI and 1.5\% per second for CGI and gray iron. Specimens with anticipated fatigue lives in excess of 500,000 cycles were switched to stress-controlled testing after 100,000 cycles and thereafter were tested at a constant frequency of 15 cycles/second. Tests were continued until a $20 \%$ drop in stress range ( $~ 50 \%$ load drop in cast iron) occurred, or until 5,000,000 cycles were reached without failure. Strain and load data were recorded during 
the tests and the test data were analyzed following the guidelines of ASTM standard E606, ASTM standard E 739-91(1998) and SAE standard J1099 JUN1998 to determine the strain-life coefficients for all materials. As previously mentioned, the ten cyclic property parameters associated with the Downing model (Downing, 1983) were determined for CGI and gray iron.

\subsection{DETERMINATION OF CYCLIC PROPERTY PARAMETERS}

The following sections describe details of the cyclic property data analyses.

\subsection{Conventional Strain-life Method}

The basic principals and analytical procedures associated with the conventional strain-life method are well documented in ASTM standard E606 and SAE standard J1099, June 1998. However, some discussion regarding noteworthy aspects of the analysis is provided below.

\subsubsection{Determination and use of elastic modulus values}

A fundamental step in the strain-life analysis of cyclic property data is the decomposition of the total cyclic strain amplitude $\left(\Delta \varepsilon_{t} / 2\right)$ into its component strains, i.e., plastic strain amplitude $\left(\Delta \varepsilon_{\mathrm{p}} / 2\right)$ and elastic strain amplitude $\left(\Delta \varepsilon_{\mathrm{e}} / 2\right)$ according to the equation:

$$
\left(\Delta \varepsilon_{\mathrm{t}} / 2\right)=\left(\Delta \varepsilon_{\mathrm{e}} / 2\right)+\left(\Delta \varepsilon_{\mathrm{p}} / 2\right)
$$

In practice, the elastic component of strain is determined by dividing the stress amplitude $(\Delta \sigma / 2)$ at specimen half-life $\left(0.5 \mathrm{~N}_{\mathrm{f}}\right)$ by the elastic modulus $(\mathrm{E})$. The plastic strain amplitude is then given as the difference between the total strain amplitude and the elastic strain amplitude. The plastic strain data determined by this method are used in the calculation of both the strainlife and cyclic stress-strain constants

As previously mentioned, the stress-strain curve of gray cast iron exhibits no linear elastic range. Thus the use of a single valued elastic modulus to decompose the total strain, as described above, is an approximation for gray iron.

Elastic modulus values determined by linear regression of the stress-strain data in an approximately linear portion of the stress-strain curve, in accordance with ASTM Standard E 111-97, were used in all the cyclic property analyses. Stress-strain data for the modulus determinations were acquired from strain gages affixed to the surfaces of tension and compression specimens as described in sections 4.5 and 4.6. The resulting elastic modulus values are presented in the material characterization section for each material in the database.

Trial analyses of the gray iron cyclic property data (as well as selected ductile iron and CGI data sets) were also conducted using initial secant modulus values; the latter were determined from the same stress-strain data as the standard modulus values. The secant modulus is the slope of a chord from zero stress and strain to a point on the stress-strain curve. It has been shown (Gilbert and Kemp,1980; Downing, 1983) that the secant modulus is a linearly decreasing function of 
stress at low to intermediate stress levels. The initial secant modulus is determined by extrapolating the linear portion of the secant modulus vs. stress curve to zero stress, thus resulting in a tangent modulus at zero stress.

Both CGI and ductile iron exhibit a proportional limit from an engineering perspective, but the secant modulus data revealed a linearly decreasing modulus for all materials examined, including ductile and compacted graphite iron. However, the initial secant modulus values differed only slightly from the standard elastic modulus values and resulted in no significant benefits analyzing the cyclic property data when used in conjunction with the conventional strain-life method. Thus, as previously mentioned, the elastic modulus values determined by the standard method were used in the conventional strain-life analysis of cyclic properties for every dataset.

\subsubsection{Plastic strain threshold}

As mentioned in the previous section, the plastic component of strain in the conventional strainlife methodology is determined as the difference between the total and elastic strains. For high cycle fatigue tests (conducted with low strain amplitudes), the plastic portion of strain can be smaller than the total or elastic strains by an order of magnitude, or more. Consequently, for such tests, relatively small uncertainties in total strain, stress amplitude or elastic modulus determination can lead to large relative errors in calculated plastic strains.

Analysis of the cyclic property data, revealed that scatter in plastic strain became pronounced only at levels below $0.01 \%$ strain. To minimize any effect of relative uncertainty in plastic strain values, a threshold for usable plastic strain data was established. Specifically, only the data from specimens with a calculated plastic strain amplitude greater than $0.01 \%\left(\Delta \varepsilon_{\mathrm{p}} / 2>0.01 \%\right)$ were used in plastic strain regressions for the determination of strain-life or cyclic stress-strain constants. Data excluded from regressions by this criterion are indicated by footnotes presented with the results.

\subsubsection{Handling runouts}

As previously mentioned, the runout criterion used in this test program was no failure after $5,000,000$ cycles. Data from test runouts were handled in the following way:

1) Conduct an initial analysis of the data, ignoring runouts as well as any other specimens tested at the same strain level that failed at lives shorter than the runouts

2) Conduct the final analysis, this time including those runouts that lie above the failure curve (predicted from analysis 1) as well as all failed specimens.

Although, this method may seem likely to produce a result that is less conservative than would result from simply ignoring runouts, it reduces bias in the results at long lives. Moreover, such bias at long lives can lead to unconservative predictions elsewhere in the curve (Conway and Sjodahl, 1991). 


\subsubsection{Determination of the cyclic stress-strain parameters}

Using data obtained from each fatigue specimen at half-life, the cyclic stress-strain constants n' (cyclic strain hardening exponent) and K' (cyclic strength coefficient) were determined by regressing the stress amplitude $(\Delta \sigma / 2)$ versus plastic strain amplitude $\left(\Delta \varepsilon_{\mathrm{p}} / 2\right)$ in logarithmic coordinates. These are related as follows:

$$
\Delta \sigma / 2=K^{\prime}\left(\Delta \varepsilon_{\mathrm{p}} / 2\right)^{\mathrm{n}^{\prime}}
$$

The cyclic stress-strain constants were also calculated directly from the strain-life constants as follows:

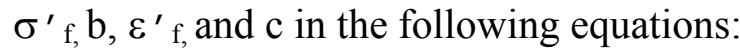

$$
\Delta \sigma / 2=\sigma^{\prime}{ }_{f}\left(2 N_{f}\right)^{b}
$$

where $\Delta \sigma / 2=$ true stress amplitude

$2 \mathrm{~N}_{\mathrm{f}}=$ reversals to failure $(1 \mathrm{rev}=1 / 2$ cycle $)$

$\sigma^{\prime}{ }_{\mathrm{f}}=$ fatigue strength coefficient

$\mathrm{b}=$ fatigue strength exponent (Basquin's exponent)

and

$$
\Delta \varepsilon_{\mathrm{p}} / 2=\varepsilon^{\prime}{ }_{\mathrm{f}}\left(2 \mathrm{~N}_{\mathrm{f}}\right)^{\mathrm{c}}
$$

where $\Delta \varepsilon_{\mathrm{p}} / 2=$ plastic strain amplitude

$2 \mathrm{~N}_{\mathrm{f}}=$ reversals to failure

$\varepsilon^{\prime}{ }_{\mathrm{f}}=$ fatigue ductility coefficient

$\mathrm{c}=$ fatigue ductility exponent

As discussed previously, the total strain is the sum of the elastic and plastic strains. In terms of strain amplitude,

$$
\Delta \varepsilon / 2=\Delta \varepsilon_{\mathrm{e}} / 2+\Delta \varepsilon_{\mathrm{p}} / 2
$$

The elastic term can be written as

$$
\Delta \varepsilon_{\mathrm{e}} / 2=\Delta \sigma / 2 \mathrm{E}
$$

We can now state this in terms of life to failure:

$$
\Delta \varepsilon_{\mathrm{e}} / 2=\left(\sigma_{\mathrm{f}}^{\prime} / \mathrm{E}\right) \times\left(2 \mathrm{~N}_{\mathrm{f}}\right)^{\mathrm{b}}
$$


The plastic term is

$$
\Delta \varepsilon_{\mathrm{p}} / 2=\varepsilon^{\prime}{ }_{\mathrm{f}}\left(2 \mathrm{~N}_{\mathrm{f}}\right)^{\mathrm{c}}
$$

The total strain can now be rewritten

$$
\Delta \varepsilon / 2=\left(\sigma_{\mathrm{f}}^{\prime} / \mathrm{E}\right) \times\left(2 \mathrm{~N}_{\mathrm{f}}\right)^{\mathrm{b}}+\varepsilon^{\prime}{ }_{\mathrm{f}}\left(2 \mathrm{~N}_{\mathrm{f}}\right)^{\mathrm{c}}
$$

This last equation is the basis of the strain-life method and is termed the strain-life relation.

Now K' and n' can also be calculated as follows:

$$
\begin{gathered}
\mathrm{K}^{\prime}=\sigma^{\prime} \mathrm{f}_{\mathrm{f}} /\left(\varepsilon_{\mathrm{f}}^{\prime}\right)^{\mathrm{n}^{\prime}} \\
\mathrm{n}^{\prime}=\mathrm{b} / \mathrm{c}
\end{gathered}
$$

Thus, the K' and n' constants were calculated by two methods, i.e., direct log-linear regression of the stress and plastic strain amplitudes and simple manipulation with the above two equations.

Although the constants obtained by the two methods are both included in the database for comparison, the data obtained from the regression analysis are deemed more reliable and only these values appear in the DATA SUMMARY file (see report section 6.0, "Results and Database Layout").

\subsection{Downing Method for Cast Iron}

The principles and practices associated with this method were developed specifically for the treatment of cast iron fatigue data and have been described by Downing (Downing, 1983). This section provides a basic overview of the Downing method and addresses specific details of its application in the present work.

\subsubsection{Downing cyclic stress-strain curve: an overview}

It is generally understood that stress-strain curves for graphitic cast iron (particularly for CGI and gray iron) exhibit curvature at relatively low stresses in comparison with the $0.2 \%$ offset yield strength. Indeed, tensile stress-strain curves in gray iron show significant curvature from the first increment of stress. For the purposes of this discussion, it should be understood that the unique properties ascribed to graphitic cast iron are manifested most significantly in gray iron, to a lesser extent in CGI and only minimally in ductile iron (Gilbert, 1961 and 1964; Palmer, 1976).

Consequently, the stress-strain curves of graphitic cast iron are not ideally represented by the familiar Ramberg-Osgood equation used for wrought metals, that is:

$$
\varepsilon_{\mathrm{t}}=\varepsilon_{\mathrm{e}}+\varepsilon_{\mathrm{p}}=\sigma / \mathrm{E}+(\sigma / \mathrm{K})^{1 / \mathrm{n}}
$$


where the above constants all represent the monotonic counterparts of the cyclic equations presented previously.

To account for curvature in the early part of the stress-strain curve, Downing modified the Ramberg-Osgood equation as follows:

$$
\varepsilon_{\mathrm{t}}=\varepsilon_{\mathrm{S}}+\varepsilon_{\mathrm{R}}=\sigma /\left(\mathrm{E}_{0}+\mathrm{m} \sigma\right)+(\sigma / \mathrm{K})^{1 / \mathrm{n}}
$$

In this modified stress-strain expression, the strain is decomposed into the secant strain $\left(\varepsilon_{\mathrm{S}}\right)$ comprised of both elastic and plastic strain, and the remaining plastic strain $\left(\varepsilon_{\mathrm{R}}\right)$. In this expression, " $\mathrm{E}_{0}$ " is the initial secant modulus (as described earlier) and " $\mathrm{m}$ " is the slope of the secant modulus vs. stress curve in the linearly varying portion of the curve at low to intermediate stresses. Thus the secant strain is simply the stress divided by the secant modulus at that stress as predicted by the regression through the linear portion of the curve.

With the onset of significant plastic deformation at higher stresses, the secant modulus begins to decrease more rapidly with stress and falls below the regression line extrapolated from the linear portion of the curve. Once this occurs, the secant strain no longer accounts for all of the strain; the difference is appropriately designated the remaining plastic strain $\left(\varepsilon_{R}\right)$. Analogous to the stress/plastic strain relationship used in the conventional Ramberg-Osgood formulation, downing demonstrated a power law relationship between stress and remaining plastic strain, as follows:

$$
\sigma=\mathrm{K}\left(\varepsilon_{\mathrm{R}}\right)^{\mathrm{n}}
$$

The monotonic stress-strain response can then be represented by four parameters $\left(\mathrm{E}_{0}, \mathrm{~m}, \mathrm{~K}\right.$ and $\mathrm{n})$. $\mathrm{E}_{0}$ and $\mathrm{m}$ can be determined from a linear regression of the secant modulus versus stress curve. After determining the remaining plastic strain as a function of stress by taking the difference between the total strain and the secant strain at each stress, $\mathrm{K}$ and $\mathrm{n}$ can be determined from a linear regression of $\log (\sigma)$ vs. $\log \left(\varepsilon_{R}\right)$ data.

Recognizing the asymmetry in the stress-strain response of graphitic cast iron, Downing treated the compression and tension responses with two separate but parallel analyses. Thus, after repeating the analysis described above in both tension and compression, the following seven parameters are determined: $\mathrm{E}_{0}, \mathrm{~m}_{\mathrm{T}}, \mathrm{K}_{\mathrm{T}}, \mathrm{n}_{\mathrm{T}}, \mathrm{m}_{\mathrm{C}}, \mathrm{K}_{\mathrm{C}}$ and $\mathrm{n}_{\mathrm{C}}$, where the subscripts indicate parameters that specifically describe stress-strain behavior in either tension or compression.

The final experimentally determined parameter used by Downing to describe the cyclic stressstrain response is the functional dependence of the unloading modulus $\left(\mathrm{E}_{\mathrm{u}}\right)$ on maximum applied stress. Gilbert and Kemp (Gilbert and Kemp, 1980) observed that the unloading modulus is a linearly decreasing function of the maximum stress from which unloading occurs. Downing regressed unloading modulus data versus maximum stress according to the following expression:

$$
\mathrm{E}_{\mathrm{u}}=\mathrm{E}_{0}+\mathrm{m}_{\mathrm{u}} \sigma_{\max }
$$

where the final stress-strain parameter is $\mathrm{m}_{\mathrm{u}}$, the stress dependence of the unloading modulus. 
In order to predict the cyclic stress strain curve, Downing utilizes these eight parameters to model the effects of each of a number of factors controlling the stress-strain response of cast iron. Specifically, the eight parameters are used to determine the "symmetrical response" of the steel-like matrix, the "reduction in effective cross-sectional area" due to graphite and surface cracking, the "compressive stress due to internal graphite constraint" and the "compressive stress due to surface crack closure".

In contrast, the conventional strain-life approach neglects curvature in the initial part of the stress-strain curve, as well as other effects of the graphite microconstituent, and treats data in terms of stress and strain amplitudes $(\Delta \sigma / 2$ and $\Delta \varepsilon / 2)$, thereby modeling properties that are effectively an average of the tension and compression responses.

\subsubsection{Potential sources of test data for cyclic stress-strain parameters}

Downing demonstrated that seven of the eight cyclic stress-strain parameters $\left(\mathrm{E}_{0}, \mathrm{~m}_{\mathrm{T}}, \mathrm{K}_{\mathrm{T}}, \mathrm{n}_{\mathrm{T}}, \mathrm{m}_{\mathrm{C}}\right.$, $\mathrm{K}_{\mathrm{C}}$ and $\mathrm{n}_{\mathrm{C}}$ ) could be derived from monotonic tensile and compression test data. The eighth parameter, the unloading modulus parameter $\left(\mathrm{m}_{\mathrm{u}}\right)$ was obtained from an incremental loading test.

However, Downing suggested that these parameters could also be derived directly from hysteresis loops obtained for the individual fatigue specimens. In this approach, maximum stress (a.k.a. peak stress), minimum stress (a.k.a. valley stress) and unloading modulus from the peak stress would be obtained for approximately 20 hysteresis loops dispersed evenly with respect to the logarithm of the fatigue life of the specimen. The peak stress, valley stress and unloading modulus data would each be plotted and regressed separately as a linear function of the fraction of remaining specimen life $\left(1-\mathrm{N} / \mathrm{N}_{\mathrm{f}}\right)$ in logarithmic coordinates. The intercept at $1-\mathrm{N} / \mathrm{N}_{\mathrm{f}}=1$ (test inception) is called the extrapolated initial value. By extrapolating to cycle zero, the data are intended to approximate the material condition in a hypothetical state that would have existed prior to the onset of cracking, but after completion of the initial transient (cyclic hardening or softening).

The three extrapolated initial values (peak stress, valley stress, and unloading modulus) from each specimen could then be used to develop the three relationships described in the preceding subsection that yield the Downing cyclic stress-strain parameters. For example, the extrapolated peak stress for a given specimen is divided by the strain amplitude to give the secant modulus. The secant modulus from each specimen is then plotted and regressed as a linear function of the extrapolated peak stress to determine $\mathrm{E}_{0}$ and $\mathrm{m}_{\mathrm{T}}$ as described in the preceding subsection. Using $\mathrm{E}_{0}$ and $\mathrm{m}_{\mathrm{T}}$, the remaining plastic strain would be calculated for each specimen thereby yielding $\mathrm{K}_{\mathrm{T}}$ and $\mathrm{n}_{\mathrm{T}}$ as described above.

In a precisely analogous manner, extrapolated initial valley stresses could be used in place of compression data to determine $\mathrm{E}_{0}, \mathrm{~m}_{\mathrm{C}}, \mathrm{K}_{\mathrm{C}}$ and $\mathrm{n}_{\mathrm{C}}$. Finally, extrapolated initial unloading modulus values from each specimen could be plotted and regressed as a linear function of extrapolated initial peak stresses to determine the unloading modulus parameter $\left(\mathrm{m}_{\mathrm{u}}\right)$.

Downing suggested that this method of utilizing data from fatigue specimens would be preferable to using tension and compression data for two reasons. First, this method utilizes data 
obtained from a large number of specimens, thereby more accurately describing the average behavior of the material. Secondly, results obtained in this way approximate the condition of the material after the initial transient, while data obtained from tensile and compression tests clearly represent the state of the material prior to mechanical cycling.

\subsubsection{Determination of the cyclic stress-strain parameters}

The suggested analyses of hysteresis data were conducted on the CGI and gray iron specimens tested at CRS. However, the analyses revealed two related problems associated with the application of hysteresis data for secant modulus versus stress regressions.

Firstly, the strain amplitudes used in the fatigue tests are generally too low to result in significant remaining plastic strain for all specimens except those with the shortest lives. Secondly, the mechanical response of gray iron and CGI varies somewhat from specimen to specimen. Since the secant modulus versus stress relationship is composed of a single data point from each specimen, the scatter in the data for a single curve is large relative to the magnitude of the remaining strain in all but a few test materials. Hence it is difficult to use the plotted information to qualitatively determine the range of data to use in the regression, i.e., it is difficult to discern the stress range wherein the secant modulus varies linearly. Moreover, there will generally be data points lying on both sides of the secant modulus regression line for stress ranges of any practical extent. Data lying above the secant modulus regression line would correspond to negative remaining strain and render solution of the power-law $\sigma$ versus $\varepsilon_{R}$ relationship by the suggested technique intractable mathematically. Consequently, secant modulus data derived from hysteresis loops were deemed unacceptable for the determination of the cyclic stress-strain parameters.

Since a given monotonic tension or compression test provides secant modulus data for the entire stress range of interest, only data from one specimen is needed for each analysis. Thus, scatter resulting from the use of multiple specimens in one regression was not encountered when using the monotonic stress-strain data. Furthermore, the stress-strain excursions in monotonic testing were more extensive than the range that could be covered during fatigue testing; therefore, the monotonic tests more clearly delineated regions wherein the remaining plastic strain was positive and amenable to analysis. Consequently, following the method demonstrated by Downing, monotonic tension and compression data were used for the secant modulus regressions for each material. To more accurately represent the average behavior of the material, multiple tension and compression tests (typically three or more) were analyzed and the results averaged for each material.

The unloading modulus data from hysteresis loops were better behaved than the secant modulus data from the same source. Moreover, only simple linear regressions are necessary for analyses of these data; calculations involving $\varepsilon_{\mathrm{R}}$ are not required. Consequently, the unloading modulus parameter $\left(\mathrm{m}_{\mathrm{u}}\right)$ was determined for each material using data from hysteresis loops as suggested by Downing. The data were taken from the first loading cycle from the fatigue tests instead of using extrapolated initial values. Unloading modulus parameters derived in this way were deemed to be more consistent with the other seven parameters which were derived from monotonic test results. 


\subsubsection{Determination of $\mathbf{E}_{0}$}

The cyclic stress-strain parameters, as outlined by Downing and as typically utilized in endurance modeling software, make allowances for only one value of the initial secant modulus $\left(\mathrm{E}_{0}\right)$. However, $\mathrm{E}_{0}$ is defined by three separate linear regressions; specifically, $\mathrm{E}_{0}$ is the zero stress intercept when the secant modulus in tension, secant modulus in compression and unloading modulus are each regressed as a function of stress. Although Downing observed that the values determined by these three methods were similar for his tests, the degree of agreement between the three values varied over the various materials tested in the present work.

For the sake of consistency, CRS established a standard method of determining $\mathrm{E}_{0}$ which was applied to all CGI and gray iron analyses. The tension and compression secant modulus data were generally better behaved than the unloading modulus data. Consequently, all four parameters $\left(\mathrm{E}_{0}, \mathrm{~m}, \mathrm{~K}\right.$ and $\left.\mathrm{n}\right)$ were determined independently in tension and compression. A final value for $\mathrm{E}_{0}$, which appears in the database, was then determined by averaging the two values from compression and tension. The unloading modulus data $\left(\mathrm{E}_{\mathrm{u}}\right)$ were then regressed with the intercept forced to this final value of $\mathrm{E}_{0}$. Thus, the slope of the unloading modulus vs. stress curve $\left(\mathrm{m}_{\mathrm{u}}\right)$ was optimized for the single value of $\mathrm{E}_{0}$ that was ultimately used in the database.

\subsubsection{Fatigue-life analysis}

The analysis of cast iron fatigue-life data via the Downing method is based on the use of a biaxial Smith-Watson-Topper (SWT) parameter $\left(\sigma_{\max }^{*} \Delta \varepsilon_{t} / 2\right)$. Fash (Fash, 1982) demonstrated a log-linear relationship between the SWT parameter and fatigue life for gray iron specimens tested in strain or in stress control. The relationship may be expressed as a simple power-law equation as follows:

$$
\sigma_{\max } * \Delta \varepsilon_{t} / 2=\mathrm{A}\left(\mathrm{N}_{\mathrm{f}}\right)^{\mathrm{b}}
$$

Only two parameters, the fatigue-life coefficient (A) and the fatigue-life exponent (b) are used to model the strain-life curve; therefore, this limits the flexibility of the model in comparison with the conventional strain-life formalism because the latter provides four "adjustable" parameters. However, the use of the above Fash relationship obviates the problematic determination of elastic and plastic strain for gray iron fatigue tests; this step is central in the analysis of fatigue data via the conventional strain-life method. Moreover, the SWT parameter provides a ready mechanism for including mean stress effects in fatigue analyses.

Stabilized behavior often does not develop during strain-controlled cycling of cast iron. Hence, the stage of specimen life at which $\sigma_{\max }$ (peak stress) should be determined is not immediately obvious. Fash and Downing demonstrated that $\sigma_{\max }$ can be taken from an initial hysteresis loop or from half-life with equally good results. Since both the tensile and compressive cyclic stressstrain parameters were derived at CRS from monotonic data, they are likely more representative of material response at the onset of cycling. For the sake of internal consistency, the peak stress values were taken from initial hysteresis loops. 
Finally, runouts in all test materials were handled exactly as in the conventional strain-life analyses (please refer to report subsection 5.1.3, "Handling runouts").

\subsection{Determination of Cyclic Properties for Contributed Data}

Fifteen datasets were contributed by private industry; eleven sets were for ductile iron, one was for gray iron and three were for austempered ductile iron (see Section 3.2). In keeping with the methods of analysis applied to ductile iron data generated at CRS, the procedures outlined above (section 5.1) were applied to calculate the conventional strain-life parameters for all sets of contributed ductile iron data. Similarly, the procedures outlined in both sections 5.1 and 5.2 were used to determine the conventional strain-life constants and the Downing parameters for the contributed gray iron data.

The conventional strain-life constants were included with the three contributed ADI datasets. These contributed parameters are used, unaltered, in the database.

\subsection{RESULTS AND DATABASE LAYOUT}

\subsection{Database Layout}

The database is presented on two "read-only" compact discs (CDROM). The CDROM database has been published by the American Foundry Society (AFS) as an AFS Research Publication entitled "Cast Iron Fatigue Properties Database for Modern Design Methods" (ISBN 0-87433267-2).

Detailed test results and analyses for ductile iron and ADI data are included on one CDROM while results and analyses for gray iron and CGI are presented on the second disc. Figures 6.1A and $6.1 \mathrm{~B}$ outline the basic layout of the two discs.

The three files contained at the main level (i.e., the root directory) provide summary information and are identical on both discs. First, the data for all materials, including basic material description, chemical composition, microstructure, monotonic properties and cyclic properties are summarized in a Microsoft ${ }^{\circledR}$ Excel file entitled "DATA SUMMARY". Within this file, a separate worksheet is provided for each of the four basic material types (i.e., Ductile Iron, ADI, Gray Iron and CGI).

The main level of each CDROM also contains this report as an Adobe ${ }^{\circledR}$ PDF file entitled "FINAL REPORT" as well as a database map contained in a file entitled "DATABASE MAP AND MATERIAL INDEX". The latter file is based on Figures 6.1 and 6.2 in this report.

Finally, two folders at the main level in each disc entitled "Ductile Iron" and "ADI", or "Gray Iron" and "CGI" lead to lower levels containing detailed data and analyses for each of the test materials in the referenced classification. As outlined in Figure 6.1, the directory structure leading to the results folder for a given test material is organized according to the following hierarchy: 
- Iron Type (ADI and Ductile Iron on Disc \#1) or (Gray Iron and CGI on Disc \#2)

- Grade Designation (e.g., Ductile Iron/ASTM A 536, 65-45-12)

- Material Code (a unique character sequence representing material condition, section-size, etc.)

The material code for each material is given along with the material description in Figure 6.1 and is repeated for each material in both the DATA SUMMARY file and the DATABASE MAP AND MATERIAL INDEX file at the main level of the database.

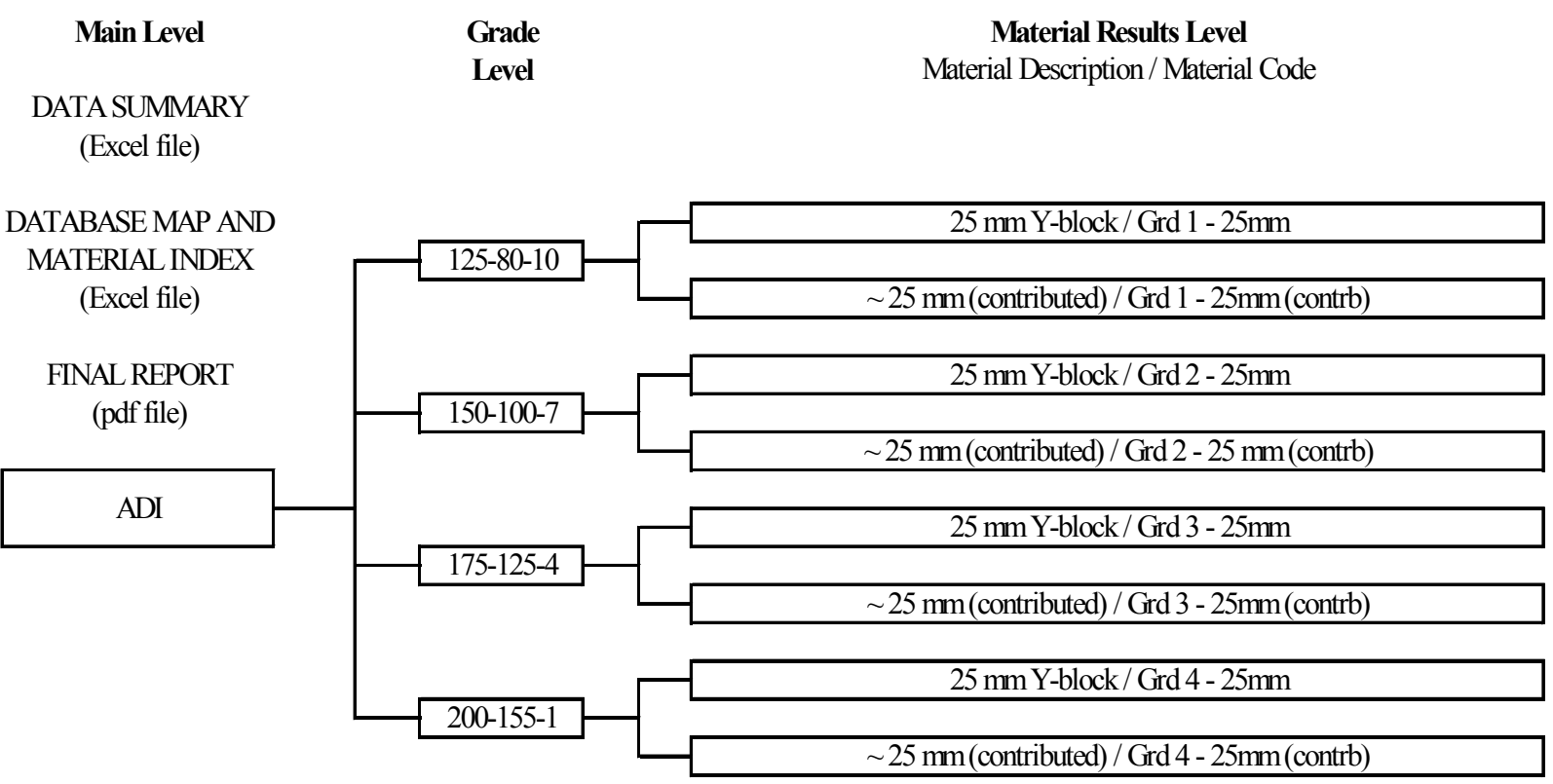

Figure 6.1a A database map and material index outlines the upper levels of CDROM \#1 (ADI and ductile iron). (continued on the following page). 
Mhin Level

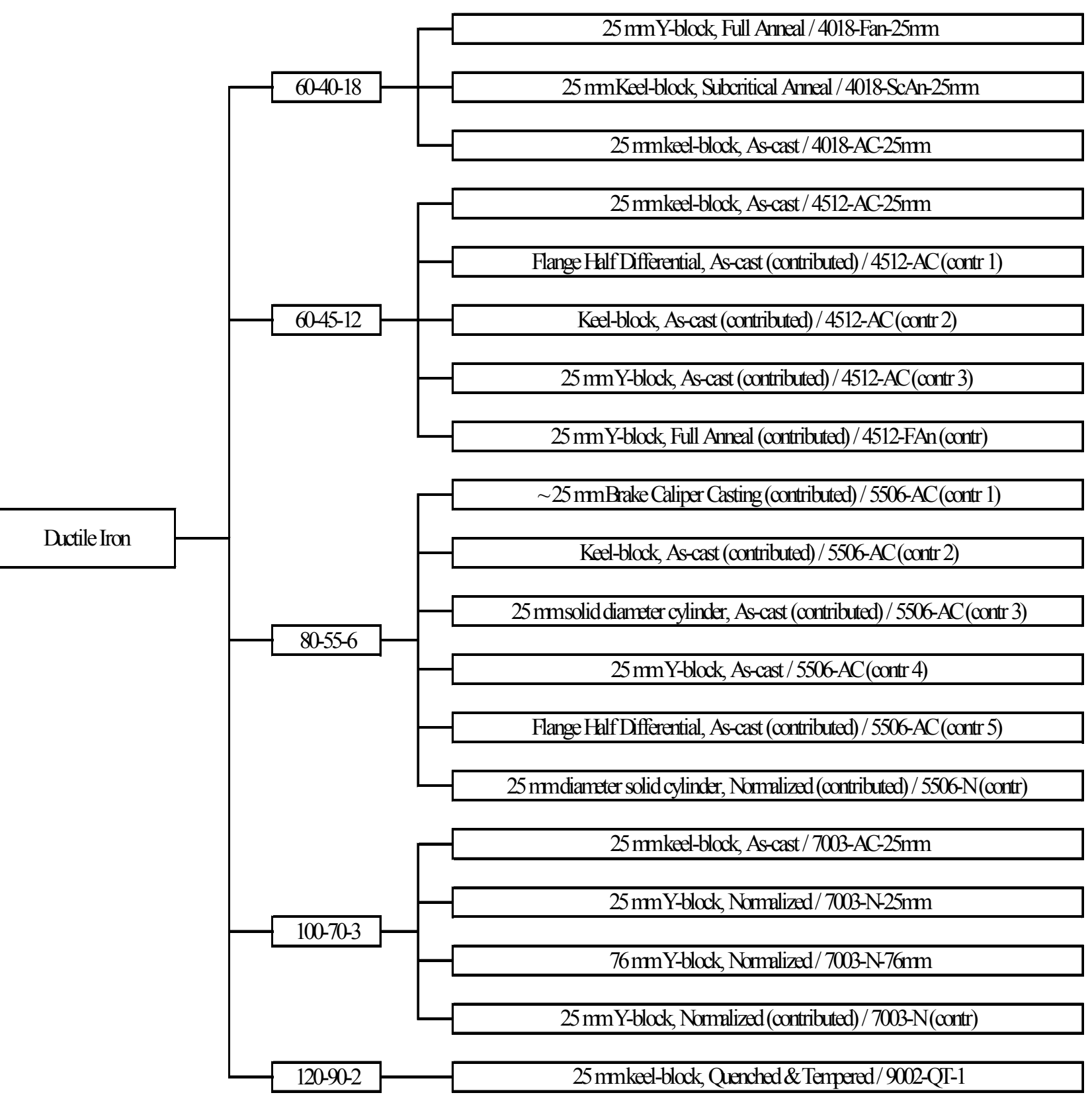

Figure 6.1a (continued). A database map and material index outlines the upper levels of CDROM \#1 (ADI and ductile iron). 


\section{Main Level}

DATA SUMMARY

(Excel file)

DATABASE MAP AND

MATERIAL INDEX

(Excel file)
Grade

Level
Material Results Level Material Description / Material Code

FINAL REPORT

(pdf file)
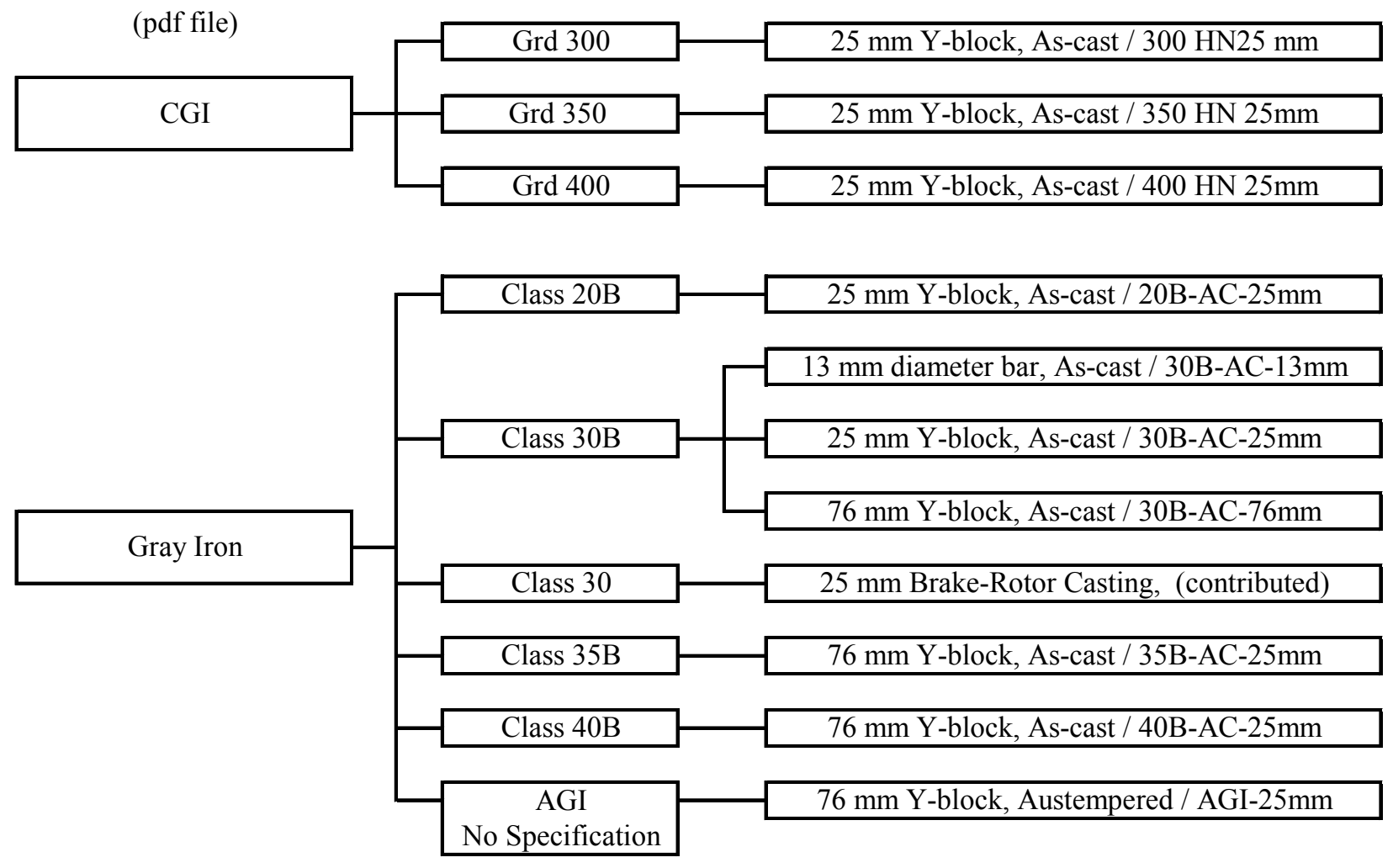

Figure 6.1b A database map and material index outlines the upper levels of CDROM \#2 (CGI and gray iron). 
The specific results files, analysis files and raw data files associated with each test material are grouped within the results folder for each material. The file structure at the results level is given in Fig. 6.2 in this report and is repeated in the DATABASE MAP AND MATERIAL INDEX file at the main level of the database. The same group of files is presented for test materials of all four basic iron types with the exception of cyclic property files associated with the Downing method, which are added for gray iron and CGI. Briefly, the files at the results level are as follows:

- Cyclic Properties Results (Downing Method): contains tabulated data for each fatigue specimen pertaining to the fatigue-life analysis according to the Downing Method. The data are plotted and relevant regressions are illustrated. Also contains tabulated results from cyclic stress-strain curve analyses for each specimen and compares the experimental data with modeled stress-strain data via relevant plots. Applies to gray iron and CGI only.

- Cyclic Properties Results (Strain-Life Method): contains tabulated data for each test specimen pertaining to the fatigue-life and cyclic stress-strain analyses according to the conventional strain-life method. The data are plotted and relevant regressions are illustrated.

- Material Characterization: contains the tabulated results from hardness testing, tension testing, compression testing, microstructural analysis and chemical analysis for each test specimen. The file also contains links to micrographs for each metallographic specimen.

- Downing Parameter Analysis: contains the stress-strain data, plots and regressions that led to the determination of the cyclic stress-strain curve parameters according to the Downing Model.

- Modulus Analyses: contains plots of the experimental stress-strain data and regressions illustrating the modulus determinations.

- Raw Data: directory containing hysteresis stress-strain data as well as raw monotonic tension and compression stress-strain data. The hysteresis files also contain plots of the hysteresis loops. Many of the raw data files from tension specimens contain extensometer data as well as strain gage data. The extensometer data were used in the determination of yield strengths, strain hardening exponents (n) and strength coefficients $(K)$. The reader is cautioned against the use of extensometer data for modulus determination. The more precise data from strain gages are more appropriate for this application.

- Micrographs: directory containing micrographs in JPEG format. 


\section{Results Levels}

Cyclic Properties Results

(Downing Method)

(Excel file)

Cyclic Properties Results

(Strain-life Method)

(Excel file)

Material Characterization

(Word file)

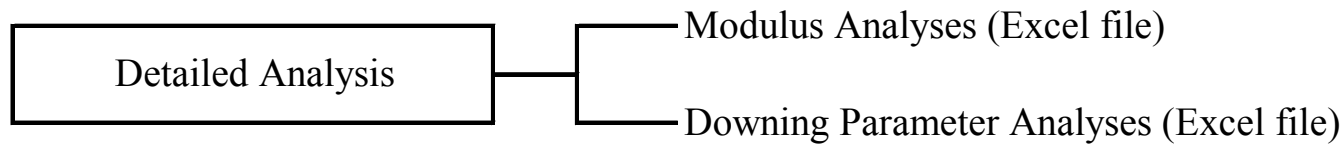

Micrographs

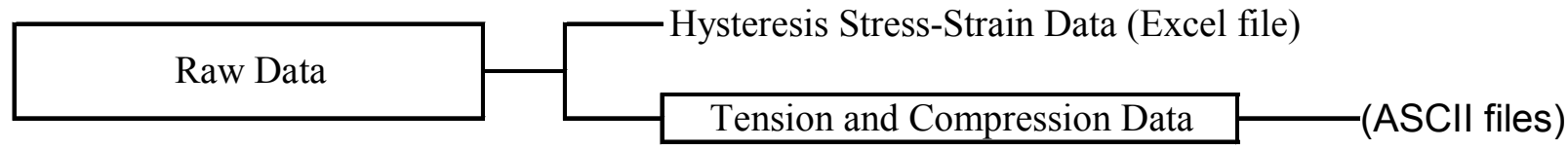

Figure 6.2 A database map details the layout of the results levels for a given material. Please note, the files "Cyclic Properties Results (Downing Method)" and "Downing Parameter Analyses" are available only for gray iron and CGI. 


\subsection{Results}

\subsubsection{Alloy composition}

The results of chemical analyses are tabulated for each chemistry sample in the "Material Characterization" file for the given material. Additionally, the averages of the elemental compositions are provided in the DATA SUMMARY file presented at the main level.

\subsubsection{Microstructure}

\subsubsection{Tabulated microstructural data}

The results of microstructural analyses are tabulated for each metallographic specimen in the Material Characterization file which appears in the folder for the given material. Averages of the microstructural results for all metallographic specimens from a given material are tabulated in the DATA SUMMARY file, which in turn is presented at the main level.

For gray cast iron, the results obtained from the test materials and from ASTM A 48 with standard Type B cast test bars are tabulated separately in the aforementioned files.

\subsubsection{Micrographs}

Digital micrographs for each specimen are provided in JPEG format in a subdirectory entitled "Micrographs" in the results folder for each material. The images can be accessed directly from the "Micrographs" subdirectory, or via links provided in the Material Characterization file.

Ideally, the micrographs should be viewed on systems with a display resolution set to at least 1024 by 768 (XGA) resolution, or the program used for display should be configured to resize the image to the screen size. Otherwise it will be necessary to scroll the image to view the micrograph in its entirety.

The magnification documented in the micrograph title simply refers to the magnification associated with the optics of the metallograph, as it was configured when the image was captured. The final display magnification obviously depends on the resolution and physical dimensions of the display area.

The issue of display magnification is simply and unambiguously addressed by referencing the micrometer scale included in the upper left corner of each micrograph (provided that the 4:3 aspect ratio of the image is not changed for display). The magnification documented in the image title is then used simply as an indication of the relative magnifications of the various micrographs.

If desired, the magnification of the displayed image on any system can be calculated from the following expression if the image resolution is not changed (i.e., the image is not "resized") during display: 


$$
\text { Display Mag. }=(\text { Optical Mag. }) \times(\text { Scale Factor }) /(\text { Display Scale })
$$

where,

- Display Mag. is the actual linear magnification of the image as displayed;

- Optical Mag. is the optical magnification from the metallograph (recorded in the image title);

- Scale Factor is the number of pixels (picture elements) at 1x optical magnification representing one millimeter on the specimen surface (Scale Factor $=6.7$ pixels $/ \mathrm{mm}$ for images in this database);

- Display Scale is the number of pixels per millimeter for the display system.

However, as previously mentioned, the inclusion of a micrometer scale in each image file has rendered such calculations unnecessary.

\subsubsection{Hardness and monotonic properties}

The results of hardness testing, tensile testing and compression testing are tabulated for each specimen in the Material Characterization file for the given material. The average values for a given parameter are tabulated in the DATA SUMMARY file.

For gray cast iron, the results obtained from the test materials and from ASTM A 48, standard Type B cast test bars are tabulated separately in the aforementioned files.

Analyses used in the determination of elastic modulus and/or Poisson's ratio are illustrated for each specimen in the Excel file entitled "Modulus Analyses" in the subdirectory "Detailed Analyses", which in turn is located in the given material directory.

Finally, raw stress and strain-data from modulus, Poisson's ratio, and $\mathrm{n}$ and $\mathrm{K}$ value determinations in both tension and compression are provided as text (ASCII) files in the subdirectory "Tension and Compression Data". This subdirectory is located in the "Raw Data" folder in the given material directory.

\subsubsection{Cyclic properties}

The cyclic properties results are presented in similar ways for both the conventional strain-life model and the Downing model.

\subsubsection{Conventional strain-life method}

The four strain-life constants [namely, the fatigue strength coefficient and exponent $\left(\sigma_{f}^{\prime}, c\right)$ and the fatigue ductility coefficient and exponent $\left.\left(\varepsilon_{\mathrm{f}}^{\prime}, \mathrm{b}\right)\right]$ as well as the two cyclic stress-strain curve parameters [namely, the cyclic strength coefficient (K') and the cyclic strain-hardening exponent 
(n')] were determined for each material. These constants are presented in the DATA SUMMARY file at the main level.

Relevant data and analyses are presented for each specimen in an Excel file entitled "Cyclic Properties Results (Strain-life Method)", which is located in the results folder for the given material. In a worksheet entitled "Strain-life", located within the aforementioned file, relevant strain-life data such as fatigue life $\left(\mathrm{N}_{\mathrm{f}}\right)$, total strain amplitude $(\Delta \varepsilon / 2)$, stress range at half-life $(\Delta \sigma)$ and plastic strain range $\left(\Delta \varepsilon_{\mathrm{P}}\right)$ for each test specimen are tabulated, plotted and analyzed. A worksheet entitled "Cyclic Stress-strain Curve", which is also included in the aforementioned file, contains relevant data, plots and regressions used in the determination of the cyclic stressstrain parameters.

\subsubsection{Cyclic properties: Downing (cast iron) method}

The ten parameters associated with the Downing cast iron formalism (namely, $\mathrm{E}_{0}, \mathrm{~m}_{\mathrm{T}}, \mathrm{n}_{\mathrm{T}}, \mathrm{K}_{\mathrm{T}}$, $\mathrm{m}_{\mathrm{C}}, \mathrm{n}_{\mathrm{C}}, \mathrm{K}_{\mathrm{C}}, \mathrm{m}_{\mathrm{u}}, \mathrm{A}$ and $\mathrm{b}$ ) were determined for each gray iron and CGI test material. These constants are presented for each material in the DATA SUMMARY file at the main level.

A file entitled "Cyclic Properties Results (Downing Method), which is located in the results folder for the given materials, contains data and analyses for each test specimen. The worksheet "Fatigue-life", within the aforementioned file contains data, plots and analyses used in the determination of the fatigue-life constants. The second worksheet, "Cyclic Stress-strain Curve", contains pertinent results for each test specimen. This worksheet also compares curves modeled from the cyclic stress-strain parameters with the test data that led to the determination of the parameters.

Finally, the data, plots and regressions that led to the determination of the cyclic stress-strain parameters are presented for each test specimen in the file entitled "Downing Parameters Analysis" " in the subdirectory "Detailed Analyses". This subdirectory is located in the results folder for the given material.

\subsubsection{Raw cyclic stress-strain data: hysteresis loops}

Hysteresis loops in the form of raw stress-strain data were saved at selected intervals throughout the life of each test specimen. The sampling intervals were most frequent near the beginning and end of tests with the frequency determined by the logarithmic decade of life. Specifically, every hysteresis loop was saved from cycle 1 through 10; loops were saved at 10 cycle intervals between 10 and 100 cycles; at 100 cycle intervals from 100 through 1000, etc. This logarithmic pattern of sampling was then repeated in reverse order from the failure cycle $\left(\mathrm{N}_{\mathrm{f}}\right)$. Typically, thirty or more loops per specimen were saved with 100 stress-strain pairs describing each loop.

The raw stress-strain data pairs for every saved cycle for a given specimen are presented in a single Excel worksheet. The worksheet also contains a plot of every saved hysteresis loop for that specimen. The worksheets for each specimen for a given material are included in an Excel file entitled "Hysteresis Stress-strain Data"; the Excel file is, in turn, located in the subdirectory "Raw Data" in the results folder for the given material. 


\subsection{RECOMMENDATIONS}

For the database to be fully effective, it must be widely accessible and it must be thorough enough to represent the range of materials designers should consider for the myriad current and future engineering applications of graphitic cast iron. These critical challenges are briefly addressed in the following two sections.

\subsection{Data Dissemination}

The CDROM database and a copy of this report has been published by the American Foundry Society (AFS) as an AFS Research Publication entitled "Cast Iron Fatigue Properties Database for Modern Design Methods" (ISBN 0-87433-267-2). Distributing the data via a CDROM database provides distinct benefits. First, given the large data capacity of a standard CDROM, the data can be presented in detail, thus meeting the various needs of most designers as well as maintaining the stand-alone integrity of the database. Secondly, the large quantities of data can be accessed efficiently from a CDROM (in comparison, for example, to downloading data via the internet). However, using an AFS Research Publication as the sole means of data dissemination may limit the visibility of the data to members of the design community.

Although presentations at professional society meetings and journal publications are impractical for data distribution they would increase the visibility of the database. SAE and/or AFS presentations and publications are recommended.

Similarly, internet publications of the data at websites associated with design and endurance modeling would provide increased visibility. The data can be efficiently hosted at a single website while links to that database can be established at other sites. Although the data presentation may be more abbreviated and data access less efficient than with a CDROM database, data distribution via the internet is practical. Moreover, the AFS CDROM database can be referenced at each website, thus alerting potential users to the more complete database available at AFS. An experimental website developed by the Fatigue Design and Evaluation Committee of SAE is an example of an appropriate site. The site administrator has expressed interest in hosting the graphitic iron database developed in this program.

Finally, commercial endurance modeling software commonly includes material databases that are integral parts of the software suite. Commercial developers of some of the most widely used endurance modeling programs have communicated their interest in adding the graphitic cast iron data developed in this program to their databases. Clearly, this method of data dissemination would be a direct and effective way of reaching the design community.

\subsection{Toward a Comprehensive Graphitic Cast Iron Database}

To enable designers to select appropriate materials and develop optimal designs with cast iron, the database should reflect the range of fatigue properties that are exhibited by the wide variety of high quality iron castings that are commercially available. 
It is generally understood that the grade designation of a cast iron (often based on monotonic properties alone) is insufficient to fully constrain the dynamic mechanical properties of the material. Strain-life data generated in this program corroborate this understanding. For example, Figures 7.1 and 7.2 demonstrate that section size is comparable to grade distinction with regard to the magnitude of its affect on the strain-life behavior of the as-cast gray iron tested in this program. However, it is impractical and unnecessary to test every grade of graphitic cast iron in all possible combinations of sizes and manufacturing histories. A more practical approach is to develop a framework that illustrates trends and establishes limits in expected fatigue behavior over well defined ranges of such key variables as material condition (heat treatment) and section size.

This approach was used to devise the test matrix for the present program. For example, Figures 7.2 illustrates the variation of fatigue response over a range of section sizes that are commonly produced in Class 30 gray iron. However, given the large number of iron "grades" for which data were needed, only a few grades of iron could be tested in multiple section sizes or material conditions. Instead, emphasis was placed on testing the most commonly produced section size and material condition for each of the grades selected.

The range of variation in section size and material conditions represented in a comprehensive cast iron database should cover common production practices. Additionally, the benefits of data for less commonly produced combinations of grade, section size and material condition should be considered when the material is associated with growing development interest, but the development is hindered by a lack of available data. For example, CGI is more commonly produced in thin sections than heavy sections; however, there is development potential for heavy-section CGI with regard to the manufacture of diesel engine blocks.

In addition to variations in section size and material condition, there are some special considerations with regard to the properties of gray iron and CGI. In gray iron, the property variations from grade to grade may be obtained in two basic ways. One method is to vary the carbon equivalent, thereby primarily affecting the strength to hardness ratio of the material. The property differences between the various grades of gray iron tested in this program were obtained largely by this method. The second method of property control is to vary the alloy content to affect the hardness of the metallic matrix. It is unlikely that the same grade of iron obtained by these two disparate methods would yield the same fatigue properties. Reflecting this complexity, the new SAE gray iron specification, SAE Standard J431 DEC2000 uses a two part classification system based on the strength-to-hardness ratio and the casting hardness. This new specification subdivides the ASTM A 48 and older SAE J431 AUG1996 grades into multiple new grades that reflect the real differences in the behavior of the materials. Adding a carefully specified series of materials to the gray iron test matrix could delineate the fatigue behavior of commonly produced gray iron with respect to these differences in monotonic properties and the newly adopted SAE grading system.

In CGI, the graphite structure (specifically, percent nodularity) is a parameter of practical significance. A maximum nodularity of $20 \%$ is specified for all five grades of CGI defined in ASTM A 842-85 (Reapproved 1997), as well as for five of the seven grades defined in SAE 


\section{LCF S train-Life C urve}

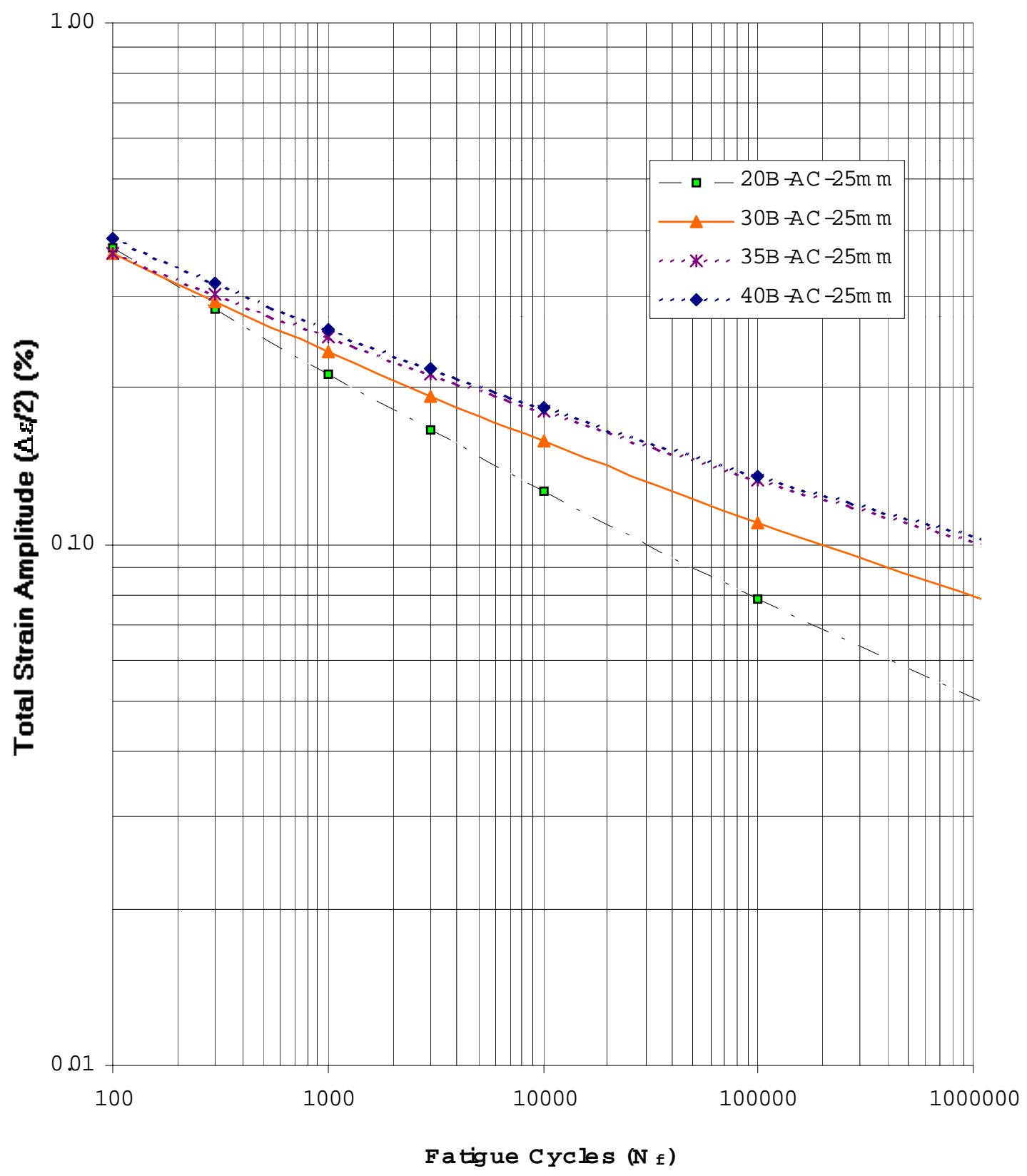

Figure 7.1 A strain-life plot comparing the fatigue behavior of Classes 20B, 30B, 35B and 40B (as cast, $25 \mathrm{~mm}$ Y-blocks) gray iron tested at CRS. 


\section{LCF Strain-Life Curve}

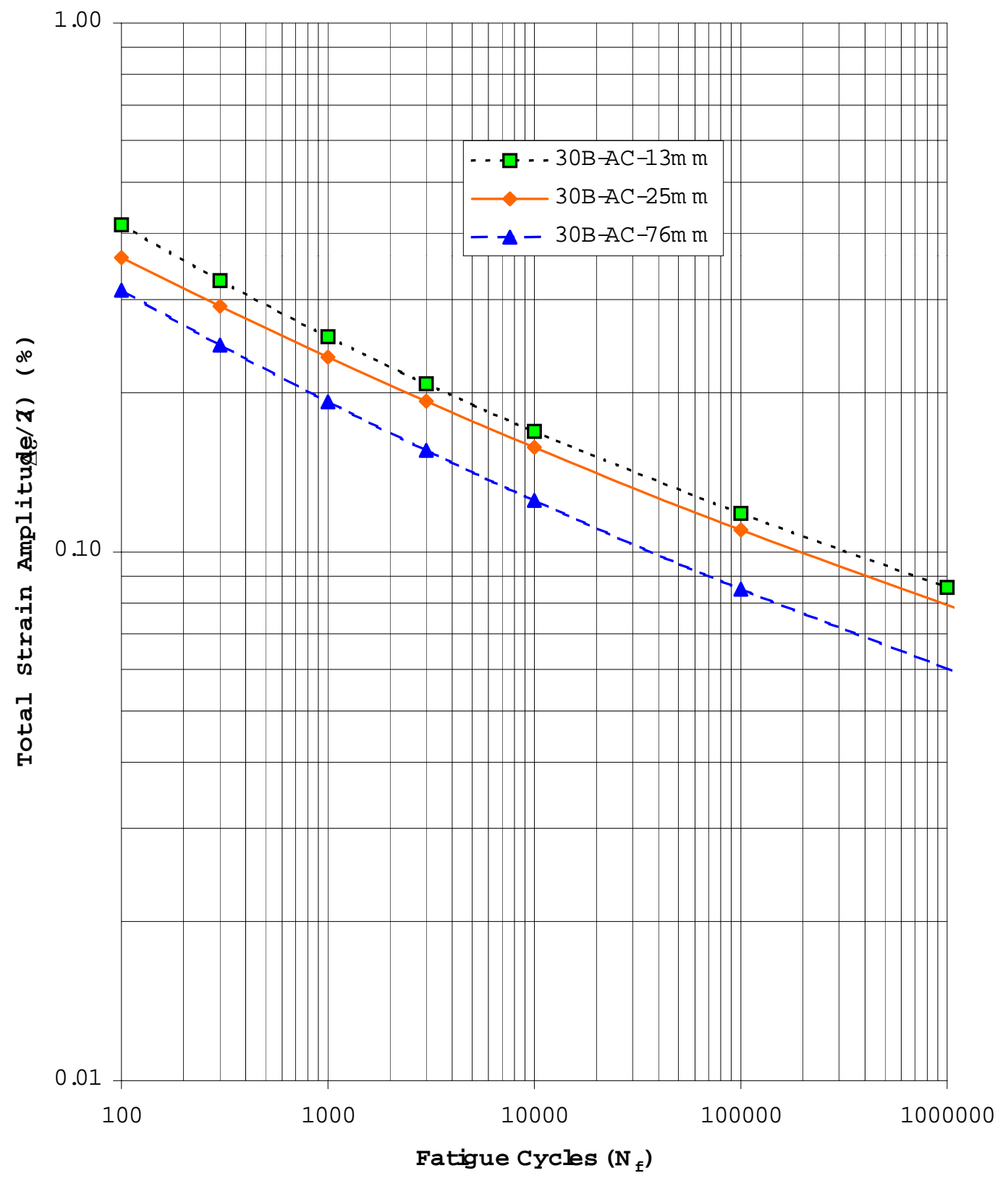

Figure 7.2 A strain-life plot comparing the fatigue behavior for three section sizes $(13 \mathrm{~mm}$ round bars, $25 \mathrm{~mm}$ Y-blocks and $76 \mathrm{~mm}$ Y-blocks) of as-cast ASTM A48 Class 30B gray iron tested at CRS. 
J1887 JUL2002. However, CGI produced in North America commonly has a nodularity that lies in the range 20 through 50 percent and this CGI is typically referred to as "high nodularity" CGI or "enhanced" CGI. The three grades of CGI tested in this program fall into this enhanced nodularity range. Improved fatigue resistance is expected in the enhanced nodularity CGI, but reliable data for comparison are unavailable. A comprehensive database for CGI should reflect the effects of section size in both the "standard" and enhanced nodularity iron.

Apart from delineating the ranges of fatigue properties of the standard types and grades of graphitic cast iron, a comprehensive database should provide data for materials with uniquely beneficial properties, but which are not defined in standard specifications. Such materials often have the greatest potential for impacting product design and manufacture, but that development is impeded by a lack of available design data. To site just a single example of such a material, "Grade 800" ADI is produced in Europe, but has not been commonly produced in North America, nor has it been included in North American standards. The microstructure of this material contains proeutectoid ferrite to enhance machinability and potentially reduce defect sensitivity. For applications requiring close dimensional tolerances, there are clear advantages associated with ADI that is production-line machinable after austempering. The manufacture and performance of such products, for which standard ADI would not likely be used, could now benefit from the many desirable properties of the "Grade 800" ADI. Recent commercial interest in this material has prompted an effort toward developing a standard specification. However, the use of this beneficial material may be curtailed by the absence of design data (specifically, strainlife data) in the public domain. 


\section{REFERENCES}

“Austempered Ductile Iron”, Ductile Iron Data for Design Engineers, Rio Tinto Iron and Titanium, section IV, pp 4-18 (1998)

Conway, Joseph B., Sjodahl, Lars H., Analysis and Representation of Fatigue Data, ASM International, Materials Park, OH (1991)

DeLa'O, J. D., Gundlach, R. B., Tartaglia, J. M., Strain-Life Fatigue Data for Cast Iron: Survey of Data in the Public Domain, p.40, AFS Research Report, Des Plaines, IL (2001)

Downing, Stephen Douglas, Modeling Cyclic Deformation and Fatigue Behavior of Cast Iron Under Uniaxial Loading, University Microfilms International, Ann Arbour, MI (1983)

Fash, J. W., Socie, D. F., "Fatigue Behavior and Mean Effects in Gray Cast Iron", International Journal of Fatigue, vol 4, no. 3, pp 137-142 (1982)

Fowler, J., Stefanescu, D. M., Prucha, T., "Production of Ferritic and Pearlitic Grades of Compacted Graphite Cast Iron By the In-Mold Process", Transactions of the American Foundrymen's Society, vol 92 pp 361-372 (1984)

Gilbert, G. N. J., "The Components of Strain Due to Deformation of the Matrix and Due to Volume Changes in a Flake Graphite Cast Iron Under Uniaxial Stress”, BCIRA Journal, vol 11, no 707, pp 512-524 (1963)

Gilbert, G. N. J., “The Stress/Strain Properties of Cast Iron and Poisson's Ratio in Tension and Compression", BCIRA Journal, vol 12, no 730, pp 170-193 (1964)

Gilbert, G. N. J., "Stress/Strain Properties of Cast Iron and Poisson's Ratio in Tension and Compression”, BCIRA Journal, vol 9, no 593, pp 347-363 (1961)

Gilbert, G. N. J, Kemp, S. D., "The Cyclic Stress/Strain Properties of a Flake Graphite Cast IronA Progress Report”, BCIRA Journal, vol 28, no 1384 pp 284-296 (1980)

Kovacs, B. V., Keough, J. R., "Physical Properties and Application of Austempered Gray Iron", Transactions of the American Foundrymen's Society, vol 101, pp 283-291 (1993)

Palmer, K. B., "Mechanical Properties of Compacted-Graphite Irons”, BCIRA Journal, vol 24, no 1213, pp 31-37 (1976)

Tartaglia, J. M., Ritter, P. E., Gundlach, R. B., Jenkins, L., Monotonic and Cyclic "Property Design Data for Ductile Iron Castings", Society of Automotive Engineers, vol 1, no. 758, (2000) 


\section{APPENDIX A}

\section{Estimating Nodularity in CGI by Ultrasonic Velocity Measurement}

During qualification testing of all three grades of CGI, metallographic analysis revealed graphite morphologies that fell outside the specified range of $20 \%$ through $50 \%$ nodularity. To surmount this obstacle, all the CGI test materials were sorted according to nodularity as determined by ultrasonic velocity measurements.

To minimize artifacts associated with material near cast surfaces, the Y-blocks from all three materials were sectioned to remove the lower cast surface (approximately 0.25 -inch thick) and then to remove rectangular test bars approximately 0.75 -inch thick. The upper and lower surfaces of each test bar were prepared for ultrasonic velocity measurements by Blanchard grinding. Three ultrasonic velocity measurements were performed on the Blanchard ground faces of each rectangular bar.

Ultrasonic velocity measurements were calibrated for nodularity determination on the basis of metallographic analysis performed on selected specimens. Six to seven test bars representing each of the three grades and having ultrasonic velocities dispersed at roughly equal intervals throughout the measured range were selected for metallographic analysis. Transverse crosssections were taken from each of the selected bars and prepared metallographically such that the plane of observation was parallel to and coincident with the vector along which the ultrasonic velocities were measured.

Image analysis for nodularity was performed on these samples in accordance with ASTM standard A247-67 (1998). To address the problem of local variability in microstructure in CGI, the number of fields sampled in each analysis was increased from the typical value. Fifty fields of view were sampled at 100x magnification on each metallographic specimen, giving a total sampled area of approximately $1 \mathrm{~mm}^{2}$ per specimen.

The results for each test group are presented in Table A1. From these data, a distinct calibration curve was developed for each of the three test materials (see Figures A1 through A3). On the basis of the calibration curves, specimens with graphite morphologies falling outside the specified $20 \%$ through $50 \%$ nodularity range were segregated from the test materials and subjected to no further testing.. 
Table A1. Nodularity vs. Ultrasonic Velocity Calibration Data

\begin{tabular}{|c|c|c|c|}
\hline & Sample ID & $\begin{array}{l}\text { Ultrasonic Velocity } \\
(\mathrm{m} / \mathrm{s})\end{array}$ & $\begin{array}{c}\text { Nodularity }{ }^{1} \\
\text { (percent) }\end{array}$ \\
\hline \multirow{6}{*}{$300 \mathrm{HN} 25 \mathrm{~mm}$} & $J 3-B$ & 5442 & 68.8 \\
\hline & J5-A & 5380 & 64.2 \\
\hline & $\mathrm{J} 10-\mathrm{A}$ & 5306 & 46.7 \\
\hline & J16-A & 5260 & 44.9 \\
\hline & J23-A & 5206 & 27.6 \\
\hline & J29-A & 5139 & 26.2 \\
\hline \multirow{6}{*}{$350 \mathrm{HN} 25 \mathrm{~mm}$} & BP19B & 5263 & 17.9 \\
\hline & BP21A & 5304 & 17.2 \\
\hline & BP26A & 5348 & 28.7 \\
\hline & ВР9В & 5388 & 33.2 \\
\hline & $\mathrm{BP} 4 \mathrm{~A}$ & 5432 & 52.2 \\
\hline & BP3B & 5478 & 58.9 \\
\hline \multirow{7}{*}{$400 \mathrm{HN} 25 \mathrm{~mm}$} & D12B & 5068 & 10.5 \\
\hline & D12A & 5120 & 11.3 \\
\hline & D4B & 5230 & 35.5 \\
\hline & D15B & 5336 & 41.1 \\
\hline & D17B & 5373 & 50.4 \\
\hline & D21B & 5407 & 53.9 \\
\hline & $\mathrm{D} 25 \mathrm{~B}$ & 5549 & 54.8 \\
\hline
\end{tabular}

\section{Footnote:}

1. Nodularity was determined from metallographic samples using image analysis. 
$300 \mathrm{HN} 25 \mathrm{~mm}$

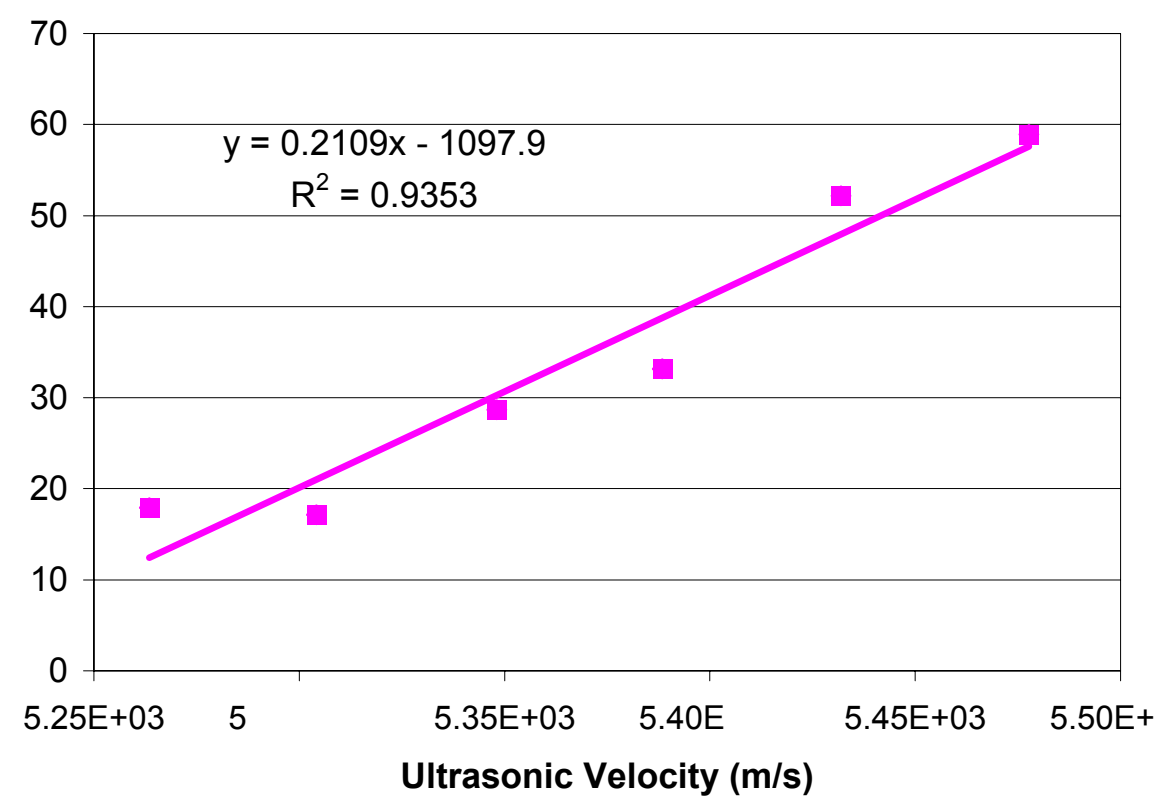

Figure A1 Nodularity vs. ultrasonic velocity calibration curve for Grade 300 CGI.

\section{$350 \mathrm{HN} 25 \mathrm{~mm}$}

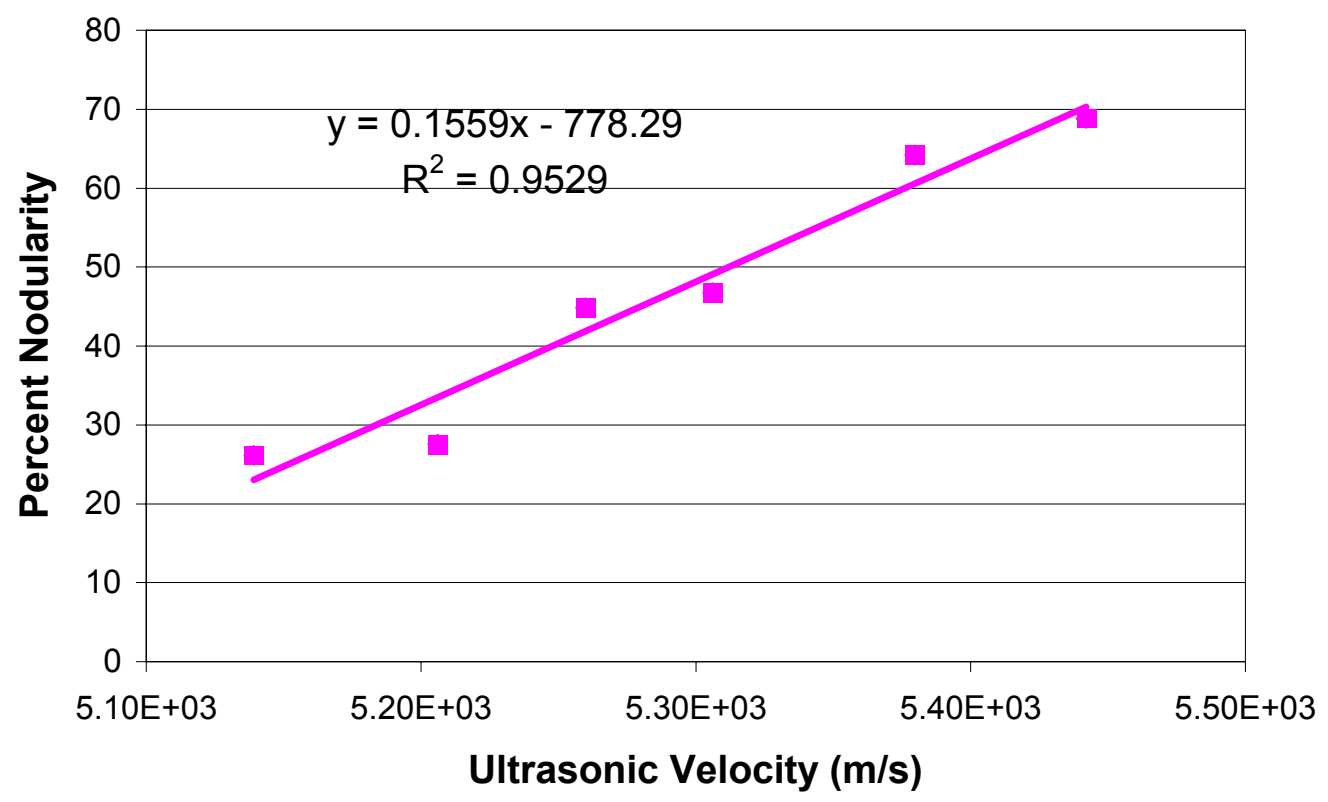

Figure A2 Nodularity vs. ultrasonic velocity calibration curve for Grade 350 CGI 
400 HN 25 mm

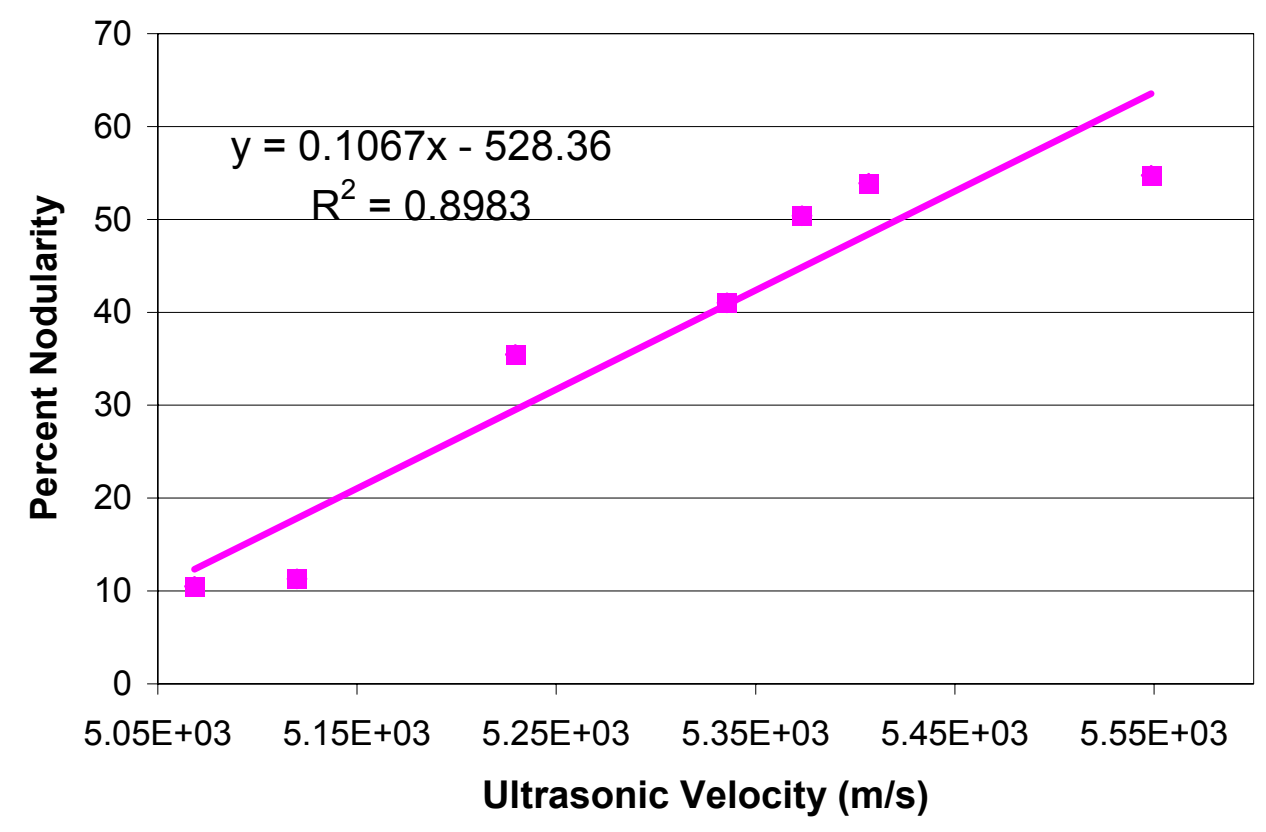

Figure A3 Nodularity vs. ultrasonic velocity calibration curve for Grade 400 CGI 